NBER WORKING PAPER SERIES

\title{
MAKING POLICIES MATTER: VOTER RESPONSES TO CAMPAIGN PROMISES
}

\author{
Cesi Cruz \\ Philip Keefer \\ Julien Labonne \\ Francesco Trebbi \\ Working Paper 24785 \\ http://www.nber.org/papers/w24785
NATIONAL BUREAU OF ECONOMIC RESEARCH
1050 Massachusetts Avenue
Cambridge, MA 02138
June 2018

This project would not have been possible without the support and cooperation of PPCRV volunteers in Ilocos Norte and Ilocos Sur. We are grateful to Adlai Newson, Judith Punzalan, and Charis Tolentino for excellent research assistance and to Prudenciano Gordoncillo and the UPLB team for collecting the data. We thank Matilde Bombardini, Pascaline Dupas as well as conference and seminar participants at UC Berkeley, the Hoover Institution, LSE, NYU, Queen's University Belfast, Queen Mary London, Stanford GSB, Stockholm School of Economics, Tsinghua, UCLA, USC, Yale, Yale-NUS and Warwick for comments. We are grateful for funding from Yale-NUS. The project received ethics approval from NUS (A-16-081) and UBC (H16-00502). The opinions and conclusions expressed here are those of the authors and not those of the Inter-American Development Bank. The views expressed herein are those of the authors and do not necessarily reflect the views of the National Bureau of Economic Research.

NBER working papers are circulated for discussion and comment purposes. They have not been peer-reviewed or been subject to the review by the NBER Board of Directors that accompanies official NBER publications.

(C) 2018 by Cesi Cruz, Philip Keefer, Julien Labonne, and Francesco Trebbi. All rights reserved. Short sections of text, not to exceed two paragraphs, may be quoted without explicit permission provided that full credit, including $(\odot$ notice, is given to the source. 
Making Policies Matter: Voter Responses to Campaign Promises

Cesi Cruz, Philip Keefer, Julien Labonne, and Francesco Trebbi

NBER Working Paper No. 24785

June 2018

JEL No. D72,P16

\begin{abstract}
Can campaign promises change voter behavior, even where clientelism and vote buying are pervasive? We elicit multidimensional campaign promises from political candidates in consecutive mayoral elections in the Philippines. Voters who are randomly informed about these promises rationally update their beliefs about candidates, along both policy and valence dimensions. Those who receive information about current promises are more likely to vote for candidates with policy promises closest to their own preferences. Those informed about current and past campaign promises reward incumbents who fulfilled their past promises; they perceive them to be more honest and competent. However, voters with clientelist ties to candidates respond weakly to campaign promises. A structural model allows us to disentangle information effects on beliefs and preferences by comparing actual incumbent vote shares with shares in counterfactual elections: both effects are substantial. Even in a clientelist democracy, counterfactual incumbent vote shares deviate more from actual shares when policy and valence play no role in campaigning than when vote-buying plays no role. Finally, a cost benefit analysis reveals that vote-buying is nevertheless more effective than information campaigns, explaining why candidates do not use them.
\end{abstract}

\author{
Cesi Cruz \\ University of British Columbia \\ 6000 Iona Drive \\ Vancouver, BC V6T 1L4 \\ Canada \\ cesi.cruz@ubc.ca \\ Philip Keefer \\ Inter-American Development Bank \\ 1300 New York Ave. NW \\ Washington, DC 20577 \\ pkeefer@iadb.org
}

\author{
Julien Labonne \\ Oxford University \\ United Kingdom \\ julien.labonne@bsg.ox.ac.uk \\ Francesco Trebbi \\ University of British Columbia \\ 6000 Iona Drive \\ Vancouver, BC V6T 1L4 \\ Canada \\ and CIFAR \\ and also NBER \\ ftrebbi@mail.ubc.ca
}

A randomized controlled trials registry entry is available at https://www.socialscienceregistry.org/trials/1210 


\section{Introduction}

Do campaign promises affect voter behavior? In less developed or hybrid democracies, voters seem to have little reason to pay attention to promises and politicians little reason to make them. Clientelism rather than policy is the currency of politics. Voters are less informed about politician performance, potentially more vulnerable to intimidation, and less able to enforce promises (e.g.,Wantchekon, 2003; Bidner et al., 2014; Keefer and Vlaicu, 2017). At the same time, recent theoretical contributions argue that even in adverse circumstances equilibria exist in which voters can eventually demand more from politicians (Bidner and Francois, 2013) and self-enforcing promises can emerge as a device to coordinate voter behavior (e.g. Aragones et al., 2007). We present results of a unique experiment in the Philippines in which, in fact, the dissemination of candidates' promises changed voter behavior.

Prior to the 2013 and 2016 elections in the Philippines, we asked all mayoral candidates in seven municipalities in the Ilocos region to state how they would allocate their local government expenditure (the local development fund) across ten categories of public goods and public services. Before the 2016 elections, voters in randomly-selected villages (barangays) received information about candidates' 2016 promises regarding all candidate allocations. In addition, some voters received information about promises made prior to the 2013 elections.

Voters who received information about 2016 promises behaved as standard spatial voting theory predicts: they were more likely to vote for candidates whose 2016 promises were closer to their spending preferences than those of competing candidates. Consistent with rational updating, these voters were more certain of their beliefs about candidates' announced policy platforms: the second moments of their belief distributions tightened compared to control voters. Their beliefs were also more accurate.

Voters who received information about both current (2016) and past (2013) promises were able to compare the campaign announcements and implemented actions of incumbent mayors. Compared to untreated voters, they were more likely to vote for incumbents who fulfilled past promises. They also perceived these incumbents as more honest and competent, pointing to a valence mechanism through which retrospective voting might operate, and not only the accountability mechanism that is the usual focus of attention. ${ }^{1}$ Voters living in barangays where promises were not kept were, if anything, more likely to punish incumbents compared to control voters.

In a clientelist setting, voters' patronage ties to politicians should affect how they react to promises. Those ties are pervasive in Ilocos: almost 20 percent of survey respondents report that they know the mayor personally, and another 41 percent of respondents report an indirect tie to the mayor through one intermediary, while 20 percent report a link to

\footnotetext{
${ }^{1}$ We use the term valence, common in the political economy literature on elections, to indicate a vector of characteristics related to quality, honesty, experience, ability as administrator, etc. of politicians. Valence is defined separately from, but not necessarily independently of, the specific policy position held by a politician.
} 
the mayor through two intermediaries. Ilocos is also the home region of former dictator Ferdinand Marcos; his family is still prominent and politically active there. Consistent with the intuition that clientelist voters have the most to lose by switching to policy-based voting, voters with ties to one of the candidates exhibited a significantly weaker response to the information treatments.

A structural model allows us to draw further lessons from the treatment. One is that the experiment not only informed voters about candidate policy commitments regarding public good allocations, it made the policy more salient. ${ }^{2}$ Disentangling the effects of information on belief updating and on salience is typically not feasible, because these interact in a voter's expected utility. The structural framework allows us to identify both mechanisms, by allowing us to hold subjective beliefs constant and explore the awareness dimension of voters.

The structural model also allows us to quantify the relative effects of vote buying, policy promises, and valence on incumbent vote share through counterfactual exercises. For example, we set vote buying to zero and ask how incumbent vote share changes when elections are clean. If vote buying were the only tool available to incumbents, a counterfactual analysis setting vote buying to zero would reduce the election to a coin flip. Instead, candidate valence (honesty and competence) and public policy platforms (through our treatment) matter substantially. The counterfactual predicts that even without vote buying, the incumbent vote share is predicted to be 59 percent, as opposed to the 65 percent that incumbents actually received (with the help of vote buying). We also explore how the vote shares of incumbents would change if they made optimal campaign announcements, centering policy on the geometric median of the ideal points of the municipal electorate.

Finally, we ask why, if providing policy information is relatively cheap and effective, do candidates engage in vote buying at all? We show that vote buying is cost-effective. Information campaigns have low costs per voter, but shift votes conditional on where the electorate ideal points are located relative to the policy announcement and what voters' prior beliefs are. Untargeted information may or may not draw more voters towards a specific candidate. Vote buying is more costly, but highly predictive of electoral support in the Philippines (Cruz et al., 2018), ultimately resulting in higher electoral returns. While politically effective, policy information has an estimated return of 16 votes per \$500 US dollars (assuming that a candidate can target voters most closely aligned with his promises). In comparison, vote buying has a return of 40 votes per $\$ 500$ US dollars spent. Private incentives are therefore insufficient for the emergence of informational campaigns, implying overall less informed electorates. The paper proves that informational campaigns are effective, but vote buying is more cost effective.

This paper relates to several strands of literature. It is closely related to scholarship

\footnotetext{
${ }^{2}$ We use the term salience (or awareness) to indicate the effect of inducing higher weight on policy dimensions in a voter's utility by shifting her attention to them.
} 
on electoral information and voter persuasion. DellaVigna and Gentzkow (2010) offer a comprehensive review of the non-laboratory evidence on voter persuasion. Kendall et al. (2015) present a broader discussion of what is considered the "minimal effects hypothesis" of political campaigning (Klapper, 1960). As in some of the most recent contributions in this line of research, we provide evidence of economically significant updating along policy and valence dimensions for candidates, in contrast to an older and more reduced-form "minimal effects" narrative, as illustrated in Bennett and Iyengar (2008). Our analysis yields a demonstration that campaign information about future policy choices affects voter behavior. In addition, while previous research has shown the effects of campaigning in mature, consolidated democracies, we identify effects in a clientelist democracy.

The fact that campaign promises influence voter behavior may seem unsurprising. Foundational work in political economy assumes that campaign promises are central to voter decision making Downs (1957). However, on the one hand, the point of departure for this work is mature democracies that exhibit partisan divisions coinciding with socio-economic cleavages and that have institutional arrangements to increase the likelihood that candidates will carry out their promises. For example, political parties have policy platforms, new parties emerge infrequently, and party-switching among politicians is rare. The Philippines and other clientelist democracies lack these arrangements.

On the other hand, even research on mature democracies has not been able to document that information about campaign promises shifts voter behavior. This is in part because it is difficult to disentangle incumbents' past policy decisions with candidates' policy promises (for example, Ansolabehere and Jones, 2010 provide evidence that the past policy votes of legislators affect voter intentions to support them). It is also due to the difficulty of interpreting electoral decision making in democracies where parties matter. Are party labels a device that voters use to summarize the policy commitments of candidates, as scholars have argued since Downs (1957)? In this case, votes for a party are also votes for the policies that the party promises to undertake. Or is partisanship a deeply-rooted psychological attachment or social identity that shapes policy preferences and voting behavior? In this case, the party's promises are not material to the electoral decision (e.g., Lenz, 2013).

Our empirical strategy addresses these difficulties. First, we can distinguish the impact of past promises from that of future promises. Second, municipal elections in a country in which parties are weak and evanescent allow us to discount the party identification effect and isolate the influence of campaign promises on voter behavior.

Our work contributes to a large body of research examining how politicians can exploit the information deficiencies of voters in the developing world (Banerjee et al., 2011). Work in the Philippines has already documented how mayors take advantage of voter ignorance: by claiming credit for central government projects (Labonne, 2013; Cruz and Schneider, 2017), or by ramping up visible infrastructure projects before the elections (Labonne, 2016). Important 
work has examined the effects on voter behavior of information on politician performance, attributes and campaign activities, though not campaign promises (Ferraz and Finan, 2008; Chong et al., 2015; Humphreys and Weinstein, 2013; Larreguy et al., 2015; Bidwell et al., 2015; Banerjee et al., 2018; Arias et al., 2018; Dunning et al., forthcoming). Other studies focus on direct appeals to reduce clientelism and vote buying (Vicente, 2014; Hicken et al., 2015). A third set of studies has elements of both (Fujiwara and Wantchekon, 2013; Gottlieb, 2014).

The information treatment that we analyze is novel in both its scope (the pure focus on past and current policy promises) and level of policy detail (ten possible types of public goods and multidimensional asymmetric subjective beliefs for voters on policy positions). We provide information on candidate promises for the current election, with a separate treatment arm in which households receive also information about past promises. Past work provides information on various aspects of the performance or attributes of politicians (criminality, corruption, attendance at parliamentary meetings, education, etc.), or instructs voters in civics, or exhorts them to refrain from participating in vote buying. Our treatments have none of this information. We inform voters of promises but say nothing about how incumbents have allocated budget resources, nor do we instruct voters to use the information about promises to assess candidate platforms or previous performance.

The information we provide is narrowly tailored to allow voters to update their subjective beliefs about the policies they think candidates will or intended to implement. The analysis of these beliefs, over multiple policy dimensions, is possible through a methodology that extends Kendall et al. (2015) to a multidimensional simplex. Our extension allows us to elicit voters' asymmetric multidimensional posterior distributions for political candidates with a parsimonious set of questions.

Our work is closest to research by Kendall et al. (2015), Bidwell et al. (2015), Brierley et al. (2018), and Cruz et al. (2018). Kendall et al. (2015) use a similar structural model to analyze the effects on voter behavior of the distribution of information on a valence issue (candidate competence and effort) and on candidate ideology. They investigate a more sophisticated electoral environment (Italian rather than Filipino municipal elections). Our data and structural model allow for a more realistic representation of beliefs than theirs. In addition, our model and data account for clientelist influences on voter behavior and allow information to operate through both salience and beliefs. We provide information on specific future policy commitments, rather than focusing on a simple left-right ideology scale, and give voters information about the campaign promises of all candidates and not only the incumbent mayors.

Bidwell et al. (2015) and Brierley et al. (2018) expose random voters to candidate debates. In the 2015 research, debate exposure increases voter knowledge about the candidates, shifts voter policy preferences to those of their preferred candidate, and increases the vote share of candidates who performed well during the debate. In the 2018 research, debate exposure 
improves voters' evaluations of candidates. The complex information content of debates is more difficult to disentangle, going beyond candidate promises and extending to candidates' interaction and the response of other audience members to the debates, a public signal of other voters' beliefs and a potential coordination mechanism. Methodologically, our structural approach allows us to quantify the respective role of beliefs and preferences, allowing us to generate policy and electoral counterfactuals.

The research here complements the research by Cruz et al. (2018). Taken together, the two experiments reveal new dynamics about the move from clientelist to programmatic politics. Their experiment took place in a group of municipalities in the Philippines that includes the seven municipalities examined here. Just before the 2013 mayoral elections, they distributed similar information about public spending and candidates' intended allocations. This was the first time that voters had been systematically exposed to information either about local public spending or about candidate promises regarding allocations. Voter ignorance should have led incumbent mayors to under- provide public goods. Consistent with this argument, treated voters in areas where the incumbents had provided fewer public goods during the 2010-2013 term were more disappointed in incumbent performance. Incumbents reacted to this disappointment by buying more votes in those areas during the 2013 elections.

Aragones et al. (2007) conclude that equilibria can emerge in which candidates make credible policy promises, even in the absence of institutional arrangements that facilitate their enforcement by voters, such as programmatic political parties. The first round of flier distribution prior to the 2013 mayoral elections might have led to a shift to such an equilibrium: the number of projects financed by incumbent mayors during the 2013-2016 term increased drastically in the municipalities in which the experiment was implemented. Eight-five percent of the sample villages in 2016 are above the threshold at which Cruz et al. (2018) find no treatment effect on vote buying. After voters were informed by a reliable source about the resources available to provide public goods and about incumbent intentions regarding public good allocations, incumbent and voter expectations regarding the Local Development Fund changed. Incumbents put more effort into providing public goods, proposed budgetary allocations became more salient, and voters and incumbents had reason to believe that voters would punish incumbents who did not fulfil their promises. By the time information about candidate promises was distributed in our 2016 experiment, the electoral equilibrium had shifted to one in which it was plausible to explore the complex effects on voter behavior of information about past and future policy promises.

In the next section we present our theoretical framework. The empirical setting, experimental design and data are described in Section 3. The reduced form estimates of the treatment effects on voters' candidate preferences are described in Section 4, while Section 5 contains the structural model and counterfactual simulations. In Section 6 we analyze the costs and benefits of using information as opposed to vote buying in our experimental 
environment. Section 7 concludes.

\section{Empirical Model}

We consider a first-past-the-post election between electoral (mayoral) candidates $A$ and $B$. Consistently with municipal decision making in the Philippines, elected mayors are assumed to be budget dictators, allocating resources across $K$ categories of public goods and administering the locality only based on their overall ability/valence. Voters are assumed to obtain utility from private consumption, a vector of $K$ public goods (in our empirical section we have $K=10$ ), and to also care about a $M$-dimensional vector of valence characteristics (competence, honesty, experience, etc.) $\mathbf{v}_{j}$ for each candidate $j=A, B$ (in our empirical section we have $M=6$ ).

Let us express each $k=1, \ldots, K$ policy variable in terms of its share of total budget $1 \geq p^{k} \geq 0$ (measured at 0.05 discrete increments in our application). The size of the total municipal budget is assumed exogenous (entirely financed by the central government). ${ }^{3}$ We normalize total budget to 1 . A policy vector $\mathbf{p}=\left[p^{1}, \ldots, p^{K}\right]$ belongs to the finite discrete policy/ideology simplex:

$$
\mathcal{P}=\left\{\mathbf{p} \in \mathbb{R}^{K}: p^{k} \geq 0, \sum_{k=1}^{K} p^{k}=1\right\} .
$$

Once elected a mayor $j$ implements a specific policy vector $\mathbf{p}_{j} \in \mathcal{P}$, which may be interpreted as the candidate's type within a citizen-candidate framework. For evidence on the realism of this assumption we refer to Ansolabehere et al. (2001) or Lee et al. (2004).

Voters are assumed to be heterogeneous in preferences, with each voter $i$ evaluating policies relative to her ideal point $\mathbf{q}_{i} \in \mathcal{P}$ and caring about the valence characteristics of the candidate $\mathbf{v}_{j}$. Before being elected, $j$ may transfer to voter $i z_{i j} \geq 0$ monetary value (in the form of vote buying, a patron-client transaction, etc.).

Let the utility of voter $i$ of type $\mathbf{q}_{i}$ be defined in the following additively separable form:

$$
U_{i}(z, \mathbf{v}, \mathbf{p})=\alpha_{i} z_{i j}+\gamma_{i} \mathbf{v}_{j}-\omega_{i} \times\left\|\mathbf{p}_{j}-\mathbf{q}_{i}\right\|^{\zeta_{i}}+\varepsilon_{i j}
$$

where $\mathbf{p}_{j}$ is policy implemented by the elected mayor $j ; \alpha_{i}, \gamma_{i}, \zeta_{i}, \omega_{i}$ are individual utility weights to be estimated; $\|.\|^{\zeta_{i}}$ indicates a generic loss function with curvature $\zeta_{i} \geq 0$, not necessarily larger than 1 (i.e. not necessarily quadratic or even convex). The deterministic component of preferences is augmented by a random utility component $\varepsilon_{i j}$ specific to the $i, j$ match. ${ }^{4}$

\footnotetext{
${ }^{3}$ For the average municipality, fixed transfers from the central government pay for 85 percent of municipal spending (Troland, 2014).

${ }^{4}$ In previous research, Kendall et al. (2015) show that interactive elements of preferences (1) (for example, between valence and policy position of a candidate) can be easily introduced in this setting, but find them to be not statistically significant. For this reason, we omit interactions from the current analysis of (1). Instead, in the same
} 
We now specify the voters' information set. Let us indicate with $\phi_{j}=\left[\phi_{j}^{1}, \ldots, \phi_{j}^{K}\right] \in \mathcal{P}$ the policy platform that candidate $j$ declares in his electoral campaign (in our empirical application these are the campaign platforms announced in 2016). Indicate with $\phi_{j}^{0} \in \mathcal{P}$ the previous term's electoral promises, available if $j$ is a repeat candidate (in our empirical application these are the campaign platforms announced in 2013). Voters are assumed to know $\mathbf{p}_{j}^{0} \in \mathcal{P}$, that is the previous term's policy, which is again only available if $j$ is the incumbent.

Individuals are uncertain about the likelihood of the actual $\mathbf{p}_{j}$ that candidate $j$ will implement once in office. Subjective beliefs may have some dispersion over the policyvalence support because voters may be uninformed about certain policy dimensions, or because of vagueness or inconsistency of campaign promises $\phi_{j}$, or because platforms may not be fully credible.

Let us indicate with $f^{i, j}(\mathbf{v}, \mathbf{p})$ voter $i^{\prime}$ s joint prior distribution function for $j=A, B . f^{i, j}(\mathbf{v}, \mathbf{p})$ is to be thought of as a discrete, but highly dimensional subjective belief distribution, different for each voter $i$ and for each candidate $j$. To see this, recall that each $p_{j}^{k}$ can take 20 values, for 10 public goods categories. Possible budget allocations are then elements of the simplex $\mathcal{P}$ which has high cardinality. ${ }^{5}$ Beliefs are also allowed to depend on individual covariates or $\mathbf{q}$ and are not required to be independent across candidates.

Our experimental strategy affects voter priors, by inducing exogenous variation in voters' information set. Exact details of the experimental design are provided below, but to fix ideas, let us consider randomly dividing voters into treatment and control groups $H \in\{\mathrm{T} 1 ; \mathrm{T} 2 ; \mathrm{C}\}$. Three experimental arms are defined. T1 voters receive a message about current policy platforms $\left\{\phi_{j}\right\}_{j=A, B}$. T2 voters receive a message about current $\left\{\phi_{j}\right\}_{j=A, B}$ and past platforms $\left\{\phi_{j}^{0}\right\}_{j=A, B^{\prime}}$, where without loss $A$ is indicated as the incumbent and $B, B^{\prime}$ the current and past challenger. $C$ voters receive no electoral message.

Finally, let us indicate with $f^{i, j}(\mathbf{v}, \mathbf{p} \mid H=h)$ is a group- $h$ voter's joint posterior distribution function, conditional on treatment status.

\subsection{Voting Behavior and Likelihood}

Before defining our choice problem, we allow for an additional margin of response for voters to $h$, namely through their preferences. Awareness or salience of specific choice dimensions may induce dependence of preferences on treatment status, reflecting, for instance, in a higher utility weight $\omega_{i}$ for a treated voter $i$ (exogenously made aware of, say, the mayor's

paper, a generic form for the loss function $\|.\|^{\zeta_{i}}$ plays a relevant role, with loss parameters statistically different from commonly assumed quadratic losses (an assumption typically imposed for analytical convenience), so we maintain flexibility along this margin.

${ }^{5}$ Even limiting $K=3$ policy dimensions and no valence, full elicitation for each candidate $j$ would require 231 questions $(=21 *(21+1) / 2)$. Direct elicitation of the individual belief distributions is, even for expert responders, unfeasible with $K=10$. 
role in education or health services provision) relative to a control voter (unaware of such dimensions for her political choice). This psychological dimension of choice has a long tradition in the literature on perceptions of salience and the importance of attributing credit or blame to politicians (Achen and Bartels, 2004; Cruz and Schneider, 2017; Grimmer et al., 2012).

For full generality, we allow $i$, conditional on treatment status $H=h$, to have preferences:

$$
\begin{aligned}
& \alpha_{i}=\alpha^{0}+\alpha^{1}(h) \\
& \gamma_{i}=\gamma^{0}+\gamma^{1}(h) \\
& \omega_{i}=\omega^{0}+\omega^{1}(h)
\end{aligned}
$$

where we normalize $\alpha^{1}(C)=\gamma^{1}(C)=\omega^{1}(C)=0$. Within our empirical environment this specification element can be tested formally and we will see below that a restricted model not allowing for salience can be statistically rejected against this more general setup.

The expected utility for voter $i$ from the election of candidate $j$ can now be defined as:

$$
\mathbb{E} U_{j}^{i}(h)=\alpha_{i} z_{i j}+\sum_{\mathbf{v}, \mathbf{p}} f^{i, j}(\mathbf{v}, \mathbf{p} \mid h) \times\left(\gamma_{i} \mathbf{v}_{j}-\omega_{i} \times\left\|\mathbf{p}-\mathbf{q}_{\mathbf{i}}\right\|^{\zeta_{i}}\right)+\varepsilon_{i j}
$$

Making use of the random utility components $\varepsilon_{i j}$, the probability that voter $i$ votes for $A$ (i.e. $i$ chooses action $Y_{i}=A$ ) can be defined as:

$$
\operatorname{Pr}\left(Y_{i}=A\right)=\operatorname{Pr}\left[\mathbb{E} U_{A}^{i}(h) \geq \mathbb{E} U_{B}^{i}(h)\right]
$$

which is used to construct the likelihood function of our problem.

Specifically, defining an indicator variable $d_{i j}=1$ for $i$ voting for $j$ and 0 otherwise, under the assumption of Type I extreme value distribution for $\varepsilon_{i, j}$, i.i.d. with $\operatorname{CDF} F\left(\varepsilon_{i j}\right)=$ $\exp \left(-e^{-\varepsilon_{i j}}\right)$, we obtain:

$$
\begin{aligned}
& \ln L(\theta)=\sum_{i=1}^{N} \sum_{j} d_{i j} \ln \operatorname{Pr}\left(Y_{i}=j\right) \\
& =\sum_{i=1}^{N} \sum_{j} d_{i j} \ln \frac{e^{\left(\alpha_{i} z_{i j}+\sum_{\mathbf{v}, \mathbf{p}} f^{i, j}(\mathbf{v}, \mathbf{p} \mid h) \times\left(\gamma_{i} \mathbf{v}_{j}-\omega_{i} \times\left\|\mathbf{p}-\mathbf{q}_{i}\right\|^{\zeta_{i}}\right)\right)}}{\left.\sum_{l=A, B} e^{\left(\alpha_{i} z_{i l}+\sum_{\mathbf{v}, \mathbf{p}} f^{i, l}(\mathbf{v}, \mathbf{p} \mid h) \times\left(\gamma_{i} \mathbf{v}_{l}-\omega_{i} \times\left\|\mathbf{p}-\mathbf{q}_{\mathbf{i}}\right\|^{\zeta}\right)\right.}\right)} .
\end{aligned}
$$

This log-likelihood relies for unbiasedness on a "missing completely at random" (MCAR) assumption for voter non-response (8 percent in our full sample). Voters supporting winning candidates, however, typically reveal their vote at differential rates relative to voters support- 
ing losing candidates. We provide evidence in Section 5 that indicates that the sub-sample of voters choosing to hide their votes is predictable, so direct estimation of the model would lead to biased estimates in our setting, as MCAR is violated. Following closely Kendall et al. (2015), we apply the choice-based approach suggested by Ramalho and Smith (2013) that allows for incorporating non-random non-response in our setting under weak assumptions. The assumption is that, conditional on the voter's actual vote, the probability with which a voter chooses to respond to the survey is constant, but this probability is allowed to depend on vote choice.

Under this assumption, it is possible to modify the log likelihood as:

$$
\ln L(\theta)=\sum_{i=1}^{N}\left[o_{i} \sum_{j} d_{i j} \ln \beta_{j} \operatorname{Pr}\left(Y_{i}=j\right)+\left(1-o_{i}\right) \ln \left(1-\sum_{j} \beta_{j} \operatorname{Pr}\left(Y_{i}=j\right)\right)\right],
$$

where $o_{i}$ is 1 if $i$ discloses the vote, and 0 otherwise. The additional $\beta_{j}$ parameters are the probabilities with which a voter discloses the vote for $j$. The first term of the log likelihood is the probability that a voter votes for $j$ and discloses his vote. The second term reflects the probability that the voter votes for one of the candidates, but chooses not to disclose his vote.

\subsection{Subjective Updating}

Part of our experimental exercise is predicated on rational updating. We spell out here the set of assumptions necessary for its interpretation.

Rational use of information (but not necessarily Bayesian updating) is our starting assumption, which we will validate empirically. The policy platforms elicited from candidates reach voter $i$ and are incorporated in her beliefs. Using Bayesian updating for expositional purposes only, this means that for any candidates $j$ :

$$
f^{i, j}(\mathbf{v}, \mathbf{p} \mid h)=\frac{\operatorname{Pr}^{i, j}(H=h \mid \mathbf{v}, \mathbf{p})}{\operatorname{Pr}^{i, j}(H=h)} \times f^{i, j}(\mathbf{v}, \mathbf{p}) \quad h=T 1, T 2
$$

As an example, one can show empirically that $f^{i, j}(\mathbf{v}, \mathbf{p} \mid H=T 1) \neq f^{i, j}(\mathbf{v}, \mathbf{p} \mid H=C)$, implying the new information triggers a change in beliefs (e.g. because voters might not have known current platforms). ${ }^{6}$

${ }^{6}$ We will also show that $f^{i, j}(\mathbf{v}, \mathbf{p} \mid H=T 2) \neq f^{i, j}(\mathbf{v}, \mathbf{p} \mid H=C)$ if $\left\|\mathbf{p}_{j}^{0}-\phi_{j}^{0}\right\|$ is low, that is when previous promises were kept so their distance from the implemented policy $\mathbf{p}_{j}^{0}$, which we measure, is low. In addition, $f^{i, j}(\mathbf{v}, \mathbf{p} \mid H=$ $T 2)=f^{i, j}(\mathbf{v}, \mathbf{p} \mid H=C)$ if $\left\|\mathbf{p}_{j}^{0}-\phi_{j}^{0}\right\|$ is high (i.e. when previous promises were not kept) and no differential role of $\left\|\mathbf{p}_{j}^{0}-\boldsymbol{\phi}_{j}^{0}\right\|$ for $H=T 1$ (because the very same lack of information about current policy inducing $f^{i, j}(\mathbf{v}, \mathbf{p} \mid H=T 1) \neq$ $f^{i, j}(\mathbf{v}, \mathbf{p} \mid H=C)$ also applies to past policy promises, inducing $f^{i, j}\left(\mathbf{v}, \mathbf{p} \mid H=T 1,\left\|\mathbf{p}_{j}^{0}-\boldsymbol{\phi}_{j}^{0}\right\| \operatorname{high}\right)=f^{i, j}(\mathbf{v}, \mathbf{p} \mid H=$ $T 1,\left\|\mathbf{p}_{j}^{0}-\phi_{j}^{0}\right\|$ low). 
We impose no restrictions on the signalling game between politicians $A, B$, and the voters. The details of such game determine the likelihood $\frac{\operatorname{Pr}^{i, j}(H=h \mid \mathbf{v}, \mathbf{p})}{\operatorname{Pr}^{i, j}(H=h)}$ and they may take a variety of theoretical forms, many discussed in the political economy literature (Chappell, 1994; Callander and Wilkie, 2007; Bernhardt et al., 2011). For instance, one could allow for beliefs on $\mathbf{v}$ to respond to information on policy $\mathbf{p}$ and cross-learning about all candidates from the policy choice of each of them. In our setting, by focusing directly on the elicited posteriors $f^{i, j}(\mathbf{v}, \mathbf{p} \mid h)$, particular restrictions on $\frac{\operatorname{Pr}^{i, j}(H=h \mid \mathbf{v}, \mathbf{p})}{\operatorname{Pr}^{i, j}(H=h)}$ are not necessary.

We also allow voter updating on relevant political events $W$ occurring in parallel to our treatment. One can think of $W$ as the set of events naturally occurring in each electoral race (at the margin of which we operate), and that affect all voters independently of treatment status. Orthogonality between $H$ and $W$, induced by the experimental design, allows us to incorporate updating based on $W$ without complication.

Further, we assume information remains local to the treated subjects and does not affect control voters. Under the Stable Unit Treatment Value Assumption (SUTVA) (Rubin, 1974, 1978), voter $i$ posterior distribution on candidate $j$ is:

$$
\begin{gathered}
f^{i, j}(\mathbf{v}, \mathbf{p} \mid h, W)=\frac{\operatorname{Pr}^{i, j}(H=h \mid \mathbf{v}, \mathbf{p})}{\operatorname{Pr}^{i, j}(H=h)} \\
\times \frac{\operatorname{Pr}^{j}(W \mid \mathbf{v}, \mathbf{p})}{\operatorname{Pr}^{j}(W)} \times f^{i, j}(\mathbf{v}, \mathbf{p}) \quad h=T 1, T 2 \\
f^{i, j}(\mathbf{v}, \mathbf{p} \mid H=C, W)=\frac{\operatorname{Pr}^{j}(W \mid \mathbf{v}, \mathbf{p})}{\operatorname{Pr}^{j}(W)} \times f^{i, j}(\mathbf{v}, \mathbf{p}) .
\end{gathered}
$$

In our reduced-form results section we will validate SUTVA extensively, focusing on the differential behavior of control subjects residing in villages with a different strength of social ties to villages populated by treated subjects or on control units geographically isolated from treated units.

\subsection{Elicitation of Subjective Posteriors}

Direct elicitation of individual belief distributions (see Manski, 2004) in this setting is unfeasible, even for expert responders. To operationalize this problem, we make a series of simplifying assumptions, while still maintaining substantial flexibility in representing complex belief structures. We show here how these assumption deliver the beliefs needed for estimation.

Let us begin discussing beliefs about candidate valence (his or her quality as an administrator, empathy, experience, honesty, etc.). Kendall et al. (2015) produce a framework where policy and valence beliefs are allowed to take on a general dependence structure. They report, however, evidence in favor of independence as a valid working assumption in the 
context of Italian elections (a copula-based method does not reject an independence assumption vis-à-vis models with dependence). As we operate with a more complex policy space, we will carry over this working assumption and allow beliefs on $\mathbf{v}$ to be independent from beliefs on $\mathbf{p}$.

We assume that voter $i$ 's beliefs about $j$ 's platform $f(\mathbf{p} \mid h)$ are unimodal and indicate the mode with $\pi_{i, j}=\left[\pi_{i, j}^{1}, \ldots, \pi_{i, j}^{K}\right]$. The vector $\pi_{i, j}$ is directly elicited by a set of survey questions, one for each $j$ :

\section{Q1 : Which budget allocation will each candidate j most likely choose?}

Figure 1 shows the representation of the policy simplex and two possible modal platforms $(0.05,0.15,0.8)$ and $(0.5,0.3,0.2)$ for the case $K=3$.

We further assume that the distribution of beliefs is local around the mode. How spread out $f_{i, j}(\mathbf{p} \mid h)$ is around $\pi_{i, j}$ depends on the degree of $i$ 's uncertainty about $j$ 's future policy choices. As second moments of high dimensional probability distributions are complex to elicit even for experts (Kadane and Wolfson, 1998; Garthwaite et al., 2012), we follow a parsimonious, yet flexible approach.

To capture the amount of probability mass each individual places on the mode of their beliefs distributions, we ask the following question concerning their overall degree of uncertainty:

\section{Q2 : How uncertain are you about the set $\left\{\pi_{i, j}\right\}_{j=A, B}$ ?}

A2 : Certain; Rather Uncertain; Very Uncertain; Don't know. $x \in\{1,2,3,4\}$

Define the probability mass $\Psi(x)$ on the mode $\left\{\pi_{i, j}\right\}_{j=A, B}$ and let us impose, based on the amount of uncertainty declared in the answer, a lower modal mass the more uncertain the voter is: $\Psi(1)=1 \geq \Psi(2) \geq \Psi(3) \geq \Psi(4){ }^{7}$

We further ask:

\section{Q3 : What budget areas are you most uncertain about? \\ A3 : $X=\{$ less than 4 areas listed $\}$}

By allowing us to focus on a specific subspace of the simplex, this final question allows us to further differentiate asymmetries across candidates in terms of higher moments of voters beliefs (e.g. skewness). Suppose $i$ indicates uncertainty about $k \in X_{i}=\{1,2, K\}$ and $i$ declares

\footnotetext{
${ }^{7}$ To see how this can help in the identification of voter beliefs, consider the answer "Don't Know" $(x=4)$. This answer indicates complete uncertainty, implying a well defined flat belief distribution. Similarly "Certain" $(x=1)$ indicates degenerate beliefs with probability mass equal to 1 on the elicited mode and 0 everywhere else on the simplex.
} 
a $x_{i}=3$ (very uncertain). Based on the answer to $Q 1$ let us define the budget share allocated over policy dimensions that are not declared uncertain as:

$$
\rho_{i, j}=\sum_{k=1, k \notin U_{i}}^{K} \pi_{i, j}^{k} .
$$

We thus use $\rho_{i, j}$ to represent the share of a budget allocation presented by each candidate $j$ about which voter $i$ is relatively more certain. Let us further define the support of the belief distribution given answers to $Q 1-Q 3$. We allow beliefs $f^{i, j}\left(\mathbf{p}_{j} \mid h\right)$ to have positive mass over the support:

$$
\begin{aligned}
& \mathcal{S}_{i, j}=\left\{\begin{array}{c}
\mathbf{p}_{j}=\left[p_{j}^{1}, \ldots, p_{j}^{K}\right] \in \mathcal{P} \\
\wedge f^{i, j}\left(\mathbf{p}_{j} \mid X_{i}, x_{i}, h\right)>0
\end{array}\right\} \\
& =\left\{\begin{array}{c}
\mathbf{p}=\left[p_{j}^{1}, \ldots, p_{j}^{K}\right] \in \mathbb{R}^{K}: \\
\text { if } k \notin X_{i}, p_{j}^{k}=\pi_{i, j}^{k} \\
\text { if } k \in X_{i}, p_{j}^{k}>0:\left\{p_{j}^{k}\right\}_{k \notin X_{i}}{ }^{\prime \prime} \sum_{s=1}^{\left(X_{i}\right)} p_{j}^{s}=1-\rho_{i, j}
\end{array}\right\}
\end{aligned}
$$

That is, support $\mathcal{S}_{i, j}$ will include, going back to our previous example, for the uncertain dimensions in $X_{i}=\{1,2, K\}$ all possible policy combinations of $\left(p_{j}^{1}, p_{j}^{2}, p_{j}^{K}\right)$ such that $p_{j}^{1}+p_{j}^{2}+$ $p_{j}^{K}=1-\rho_{i, j}$, while all other dimensions $k \notin X_{i}$ will be left at the modal values. Notice that by definition $\pi_{i, j} \in \mathcal{S}_{i, j}$.

Concerning the beliefs probability distribution $f^{i, j}\left(\mathbf{p}_{j} \mid h\right)$ we assume a linear decay of a total $1-\Psi_{j}\left(x_{i}\right)$ probability mass off the mode along all policy dimensions in $X_{i}$, while leaving $\Psi_{j}\left(x_{i}\right)$ probability mass on the mode. Notice that we are able to allow a different $\Psi_{j}\left(x_{i}\right)$ for any candidate $j$. More precisely, we employ:

$$
\begin{aligned}
f^{i, j}\left(\mathbf{p}_{j} \mid h\right) & =\left\{\begin{array}{cc}
0 & \text { if } \mathbf{p}_{j} \notin \mathcal{S}_{i, j} \\
\left(1-\Psi_{j}\left(x_{i}\right)\right) \times w\left(\mathbf{p}_{j}\right) & \text { if } \mathbf{p}_{j} \in \mathcal{S}_{i, j}, \mathbf{p}_{j} \neq \pi_{i, j} \\
\Psi_{j}\left(x_{i}\right) & \text { if } \mathbf{p}_{j}=\pi_{i, j}
\end{array}\right. \\
\text { where } w\left(\mathbf{p}_{j}\right) & =\frac{1-\left\|\mathbf{p}_{j}-\pi_{i, j}\right\|}{\Omega} \\
\text { and } \Omega & =\sum_{\mathbf{p}_{j} \in \mathcal{S}_{i, j}}\left(1-\left\|\mathbf{p}_{j}-\pi_{i, j}\right\|\right)
\end{aligned}
$$

and where ||. || indicates Euclidean distance.

Our approach noticeably reduces the complexity of the elicitation process in a highly dimensional space. The presence of a detailed elicitation of $\pi_{i, j}$ plus the additional information on $X_{i}$ allows us to indirectly capture the perceived asymmetry across candidates in the $i^{\prime} s$ 
beliefs distributions based on the different $\rho_{i, j}$. Under a linear decay assumption away from the mode, if for example voter $i$ indicates $\rho_{i, A}>\rho_{i, B}$ and there is an identical probability mass on the mode $\Psi\left(x_{i}\right)$ for both $A$ and $B$, it must follow that voter $i$ 's considerations about uncertainty mostly concern candidate $B$ as the policy dimensions in $X_{i}$ account for a larger share of policy budget for him/her.

\section{Institutional Setting, Experiment, and Data}

There are 1,489 Philippine municipalities, each governed by a mayor, elected at-large every three years. The Local Government Code passed in 1991 devolved a number of responsibilities to municipalities, including local infrastructure projects, health and nutrition initiatives, and other client-facing services (Khemani, 2015; Llanto, 2012). In turn, the federal government implemented a system of fixed transfers to the municipalities, which constitute 85 percent of municipal spending (Troland, 2014). Laws governing transfers to municipalities encourage municipalities to allocate 20 percent of transfers to development projects.

Mayors exercise broad budgetary discretion and control over municipal spending priorities. As a result, unlike politicians in the national legislature or local politicians in other countries without executive powers, voters in the Philippines can reasonably attribute municipal spending and programs to the efforts of their mayor (Cruz and Schneider, 2017). Philippine mayors are often characterized as 'budget dictators' who are not subject to any meaningful institutional checks and balances (Capuno, 2012; Sidel, 1999).

As in many other democracies in the developing world, Philippine politics is characterized by clientelist politics. Campaigns tend to have little or no policy content and parties are more likely to be known for personalities or family alliances than for platforms and programs (Hutchcroft and Rocamora, 2003; Kerkvliet, 2002).

Vote buying is prevalent and widely accepted, and the price per vote generally ranges between PHP 100 to PHP 1,500 per household (approximately $\$ 1.96$ to $\$ 29.50$ USD). The price per vote does tend to vary as a function of local economic conditions and the competitiveness of local elections. In our study area, the vote buying rates tend to be higher than in other parts of the country: around $\$ 20-\$ 50$ per household (which typically includes at least 4 voting age individuals). These are significant amounts, given that the poverty threshold in 2015 were PHP 302 (\$ 5.83) per day for a family of 5. Twenty-one percent of the population falls below that threshold. ${ }^{8}$

\footnotetext{
${ }^{8}$ Source: https://psa.gov.ph/content/poverty-incidence-among-filipinos-registered-216-2015-psa visited on May 4, 2018.
} 


\subsection{Design of the Experiment}

Our experimental design spans two consecutive mayoral elections in the Philippines, in 2013 and 2016. A few weeks before each of the elections, survey enumerators collected data from every mayoral candidate in order to produce fliers that described the candidate spending priorities and policy promises. ${ }^{9}$ A non-governmental organization, the Parish Pastoral Council for Responsible Voting (PPCRV), distributed the fliers containing the information collected from candidates to all households in randomly selected villages in the days leading up to the elections. $^{10}$

The two-arm treatment design allows us to assess the effect of two specific types of information necessary for voters to evaluate the candidates for office: (i) what candidates propose to do if elected; and (ii) whether the incumbent politician kept her previous policy promises. Households in the first treatment arm (T1) received only the fliers produced in 2016, containing the information provided by the current candidates for office. Households in the second treatment arm (T2) received both the 2016 and the 2013 fliers for their municipality. The 2013 fliers have identical formatting as the 2016 fliers. Since 2016 incumbents were necessarily candidates in 2013, the 2013 fliers contain the proposed budget allocations that were made by the current incumbent mayor. We did not explicitly inform voters whether their incumbent mayor kept the budgetary promises from 2013. This intervention was perceived as invasive and antagonistic by candidates in our preliminary interaction phase with them. Instead, we provided voters with information necessary to make this assessment, in combination to their own local knowledge.

The candidate data collection process was identical in 2013 and 2016. Candidates were told that the information they provided would be given to randomly-selected barangays in their municipality prior to the election, but not which ones. In the course of the interview, we gave each candidate a picture worksheet with a list of ten sectors. Candidates were asked to allocate money across sectors. To facilitate this exercise, candidates received 20 tokens to place on the worksheet and were told that each token represented five percent of the total budget. ${ }^{11}$

Villages were allocated to $\mathrm{T} 1, \mathrm{~T} 2$ and control using a pairwise matching algorithm. ${ }^{12}$ The

\footnotetext{
${ }^{9}$ Candidates were identified using the official list of registered candidates produced by the Commission on Elections (COMELEC). The information campaign was designed to incentivize participation: most candidates were eager to participate (only one refused in 2013 and all agreed in 2016), even contacting PPCRV to ensure that they would be included. Incumbent willingness to participate may appear puzzling, given that the effect of the information treatment was to decrease incumbent support in 2013 (Cruz et al., 2018). However, since incumbents knew that the flier would be distributed regardless of their participation, their best response was to ensure that at least their own spending priorities and programs would also be shared with voters.

${ }^{10} \mathrm{~A}$ copy of the 2016 flier is included as Figures A.1 and A.2. The translation is available in Table A.3.

${ }^{11}$ Candidates took this task seriously, considering their allocations carefully and often moving chips around several times before being satisfied with their allocation.

${ }^{12}$ First, for all potential triplets, the Mahalanobis distance was computed using number of registered voters, number of precincts, an urban/rural dummy, incumbent vote share in the 2013 elections, prevalence of votebuying in 2013, salience of budget allocations in 2013 and knowledge of electoral promises in 2013. Second,
} 
final sample includes 158 villages: 54 T1, 50 T2 and 54 control villages in seven municipalities. (cf. Table A.1).

PPCRV prepared fliers showing the proposed allocations of all candidates in each municipality for both the 2013 and 2016 elections. Then, in the week leading up to the election, trained PPCRV volunteers distributed the fliers to all households in target villages through door-to-door visits. The teams were instructed to visit all households in the village and give the flier (or fliers in T2) to the head of household or spouse, and in his or her absence, a voting-age household member. ${ }^{13}$

For each household visit, volunteers used a detailed script to explain the information campaign to voters. The script emphasized the following: (i) the distribution of fliers is part of the PPCRV's non-partisan voter education campaign; and (ii) the information contained in the fliers came directly from the candidates themselves. Visits lasted between 5 and 10 minutes and volunteers left a copy of the flier. No households refused the fliers. Neither the flier nor the script instructed voters on what conclusions to draw from the information. A detailed timeline of the experiment is available in Table A.2. The experiment was registered on the AEA RCT registry on May $5,2016 .{ }^{14}$

The results in Table A.5 indicate that the village-level variables used to carry out the pairwise matching exercises are well-balanced across the treatment and control groups. We also use data from the survey to test if the treatment and control are balanced with respect to household composition, households assets, etc. Overall the groups are well balanced. ${ }^{15}$

\subsection{Data}

We implemented a detailed household survey in 158 villages shortly after the May 2016 elections. In each village, the field team obtained the official list of registered voters and randomly selected 22 individuals to be interviewed for a total sample size of 3,476. Descriptive statistics for the variables not displayed in the balance tests tables are available in Table A.8.

Vote Choice. We collected data on respondents' vote choice. In order to reduce the tendency of respondents to claim they voted for the winner when they did not, we used a secret ballot protocol. $^{16}$

the partition that minimized the total sum of Mahalanobis distance between villages in the same triplets was selected. Third, within each triplet, a village was randomly selected to be allocated to T1, a village was randomly selected to be allocated to T2; the other one serving as control. In two cases, the number of villages was not a multiple of 3 and we created a pair instead of a triplet. In those cases, a village was randomly allocated to T1; the other serving as control.

${ }^{13}$ Due to time constraints, there were no additional visits on different days if no voting-age household member was present on the day of the visit. Our enumerators did not report problems with contacting households with the fliers.

${ }^{14}$ Relevant documents are available at https://www.socialscienceregistry.org/trials/1210

${ }^{15}$ This set of results is available in Table A.4-A.7.

${ }^{16}$ The protocol was implemented as follows. Respondents were given ballots with only ID codes corresponding to their survey instrument. The ballots contained the names and parties of the mayoral candidates in the 
Across the seven municipalities where our experiment took place, incumbents won 68.5 percent of the vote, on average. The vote choice data collected using this module are reliable and unaffected by the treatment. The votes reported by subjects are highly correlated with votes in precinct-level results that correspond to respondent villages. The correlation between official incumbent vote share at the village level and incumbent vote share computed from our sample is 0.77 . The correlations are identical in the treatment (0.77) and control groups (0.78). In addition, the likelihood of refusing to answer the vote choice question is similar between the treatment (6.9 percent) and control (8.1 percent) group ( $p$-value 0.243 ).

Voter preferences over budget spending. We used the same method as the one used to elicit candidate promises to ask respondents about their ideal policy allocations q. Respondents were given a picture worksheet with a list of ten sectors. Enumerators informed them of the amount of their local development fund and that local governments face a number of options in terms of how to allocate a budget. Then respondents were asked to consider their own preferences for allocation.

This approach was developed by Cruz (2013) to reduce the cognitive demands of expressing preferences in situations where there are multiple choices with explicit and clear trade-offs. The combination of picture worksheets and tokens is especially helpful for respondents with lower levels of literacy and numeracy. As in the candidate survey, respondents took this task seriously; considering their allocations carefully and often moving tokens around several times before being satisfied with their allocation.

Voter beliefs about candidate policies. We then collected data on voter beliefs about the proposed policies of candidates $\mathbf{p}$. Direct elicitation of those beliefs is not possible in this context, as they are high dimensional objects, necessitating adjustments to reduce the cognitive demands of the survey modules. To collect data on voter beliefs about candidates' policies, after voters expressed their own policy preferences (as described in the previous section), enumerators asked them to repeat the exercise-this time considering what they think the preferred allocations of the candidates are. To facilitate direct comparison across candidates and reduce bias resulting from the order that the candidates were considered, respondents were asked to consider allocations for all candidates, one sector at a time (sectors were also shuffled to reduce concerns with question order). Respondents were given a set of poker chips that they could allocate to each sector, with a different color for each candidate. As in the previous exercise, once respondents completed the worksheet, they were given an opportunity to review and reallocate their poker chips as needed.

municipality, in the same order and spelling as they appeared on the actual ballot. The respondents were instructed to select the candidate that they voted for, place the ballot in the envelope, and seal the envelope. Enumerators could not see the contents of these envelopes at any point and respondents were told that the envelopes remained sealed until they were brought to the survey firm to be encoded with the rest of the survey. 
After respondents completed the exercise, enumerators then asked them how certain they were, across all candidates, of their allocations. While asking about the allocations of each candidate at a time would allow for a separate measure of certainty of beliefs for each candidate, this would be too cognitively demanding for voters. Pre-testing the modules showed that when voters were faced with having to do the entire allocation for each candidate at a time and then assess their certainty about the candidate's allocation, they would complete the exercise seriously for the first candidate but then tend towards merely repeating the allocation and their reported certainty for the subsequent candidates. By contrast, having respondents assess the allocation for all candidates one sector at a time made it cognitively easier for them compare and contrast between candidates. The procedure described in detail at the end of Section 2.3 shows how this information then allowed to recover beliefs distributions for all voters and different for each candidates.

Voter beliefs about candidate valence. We collected data on voters' beliefs about candidate valence along the following dimensions: (i) Approachable/Friendly; ${ }^{17}$ (ii) Experienced in politics; (iii) Honest; (iv) Politically well-connected; (v) Gets things done; (vi) Understands the problems of citizens like me. Again, in order not to excessively load the cognitive requirements of our survey, we avoided eliciting from voters the full distribution for $\mathbf{v}$, which would have been as demanding as the distribution of $\mathbf{p}$. We opted for a simpler elicitation for valence, by focusing on which $j$ candidate dominates in expectation along each of the six dimensions. ${ }^{18}$ As voter preferences are linear and monotonically increasing along all valence dimensions, this is in fact the relevant information needed for $\mathbf{v}$ in the computation of $\operatorname{Pr}\left(Y_{i}=j\right) .{ }^{19}$

Similarity. We expect the treatment to cause voters to select candidates whom they believe will pursue policies that are closer to how voters want the budget to be allocated. We compute

\footnotetext{
${ }^{17}$ Although "approachability" in the Philippine context is related to clientelism and refers to the ability to make requests or "approach" a politician for favors, this is distinct from our measure of clientelist ties. Extensive pre-testing of this question and the questions on ease of access to clientelist goods suggest that respondents differentiate between approachability or helpfulness in general and clientelist access specific to an individual.

${ }^{18}$ The question was worded as follows: "Now we're going to show you a set of worksheets-one for each candidate- as well as some flashcards containing some traits that candidates might have. For each of these traits, please place them on the worksheet of the candidate that you most associate with that trait. You may place the same trait on both worksheets or you may choose not to place a trait at all if you feel that it doesn't apply to any of the candidates."

${ }^{19}$ More formally, the expected utility for voter $i$ from the election of candidate $j$ where for each valence dimension $m$ can now be defined through $M$ indicator functions $I()_{i}^{m}$ taking value 1 if, according to $i, j$ dominates along dimension $m ; 0$ otherwise:$$
\mathbb{E} U_{j}^{i}(h)=\alpha_{i} z_{i j}+\sum_{m} \gamma_{i}^{m} I(\mathbf{v})_{i}^{m}-\sum_{\mathbf{p}} f^{i, j}(\mathbf{p} \mid h) \times\left(\omega_{i} \times\left\|\mathbf{p}-\mathbf{q}_{\mathbf{i}}\right\|^{\zeta_{i}}\right)+\varepsilon_{i j} .
$$ 
the similarity between voter $i$ ideal point $\mathbf{q}_{i}$ and modal candidate $j^{\prime}$ s policy $\boldsymbol{\pi}_{i, j}$

$$
\text { Similarity }_{i j}=1-\sqrt{\frac{1}{2} \sum_{k=1}^{K}\left|\pi_{i, j}^{k}-q_{i}^{k}\right|^{2}}
$$

We compute the similarity measure over a number of different sectors: for individual $i$ 's top sector, top 2 sectors, top 3 sectors as well as for health, education and agriculture (the three main sectors), and all sectors. These alternative measures are useful to ascertain the possible fragility of our results to imposing excessive policy detail (e.g. $K \neq 10$ ) or cognitive overload from focusing on irrelevant dimensions.

clientelist ties. We also expect that voters with clientelist ties to one of the candidates will respond more weakly to our information treatment. To capture clientelist ties, we asked voters how easily they can access a series of common clientelist goods (on a 10-point scale). We then classify voters as clients along that dimension if they are above the median. We measure this along the following dimensions: ease with which they can ask politicians to pay for medical expenses, to provide an endorsement letter for a job or to pay for funeral expenses. In addition, we asked respondents to report information on their links to the mayor. 18 percent of survey respondents report having a direct link with the mayor. 41 percent of respondents report an indirect link to the mayor through one intermediary (distance of two from the incumbent) and the remaining 42 percent report an indirect link to the mayor through two or more intermediaries (distance of three or higher). We code individuals as clients if they are connected to the mayor through a politician (e.g. barangay captain, councilor, etc.). About 15 percent of our respondents fall into that category.

Fulfilling promises. We use data from the household survey to measure the incumbent mayors' sectoral allocations during the 2013/2016 term. Each respondent can list up to 5 projects implemented by the municipality between 2013 and 2016. We start by matching those responses to the 10 sectors included in the fliers and count the number of projects in each sector by each respondent. We then aggregate the individual-level responses to the village-level and compute the share of projects in each sector $\left(p_{k}^{0}\right)$. This allows us to compute a measure of similarity between projects implemented between 2013 and 2016 in each village and incumbent promises made prior to the 2013 elections $\left(\phi_{k}^{0}\right)$ :

$$
\operatorname{Similarity}_{p}^{\phi^{0}}=1-\frac{1}{\mu} \sqrt{\sum_{k=1}^{K}\left|p_{k}^{0}-\phi_{k}^{0}\right|^{2}}
$$


Where $\mu$ ensures that the measure is between 0 and $1 .^{20}$ To indicate incumbents that have fulfilled their promises in a village, we created a dummy variable, Kept, which equals one when Similarity $y_{p}^{\phi^{0}}$ is greater than 0.5; zero otherwise.

To validate data from the household survey, we also collected data from municipal accountants and engineers on projects implemented by the municipality between 2013 and 2016 (and their cost). The data is collected at the municipal-level. We can compute budget shares and compare them to the project shares computed from the household survey. Table A.9 presents those comparisons. The shares are remarkably similar across the two methodologies and two methods of aggregating the household survey data.

\section{Reduced-Form Estimation}

This section first shows that voters respond to the information provided by the experiment in ways consistent with the model discussed in Section 2. Treated voters incorporate complex information about candidate promises when deciding for whom to vote. Their subjective beliefs about candidate policy positions change. Then we show that voters are more likely to vote for incumbents that keep their past promises. This operates through a change in beliefs about valence. When voters become aware of incumbents' past promises and those promises match actual policy, voters consider incumbents more honest and competent. Finally, we show that clientelist ties render informational treatments irrelevant.

\subsection{Treated voters are more likely to vote for the candidate whose policies are closer to their own preferences}

We start by estimating regressions of the form:

$$
Y_{i v l}=\delta^{0} T_{v l}+\delta^{1} \Delta \text { Similarity }_{i v l}+\delta^{2} T_{v l} \times \Delta \text { Similarity }_{i v l}+v_{l}+u_{i v l}
$$

where $Y_{i v l}$ is a dummy equal to one if individual $i$ in village $v$ in triplet $l$ reported voting for the incumbent in the 2016 elections. $T_{v l}$ is a dummy equal to one if the intervention was implemented in village $v$. $\Delta$ Similarity $_{i v l}$ is the difference between the similarity of voter $i^{\prime} s$ ideal point and the subjective mode for the incumbent and the similarity of voter $i$ 's ideal point and the subjective mode for the challenger. ${ }^{21}$ As we randomized within triplets, all regressions include a full set of triplet fixed effects. Given that the treatment is assigned at the village-level, standard errors are clustered at the village-level. The coefficient $\delta^{1}$ in equation (3) captures the extent to which individuals vote spatially to begin with (i.e. in the control

\footnotetext{
${ }^{20}$ It is the maximum of $\sqrt{\sum_{k=1}^{K}\left|p_{k}^{0}-\phi_{k}^{0}\right|^{2}}$ for incumbents in our sample. Practically in our sample it is 83.96.

${ }^{21}$ In cases where we have more than one challenger, we take the difference between the incumbent and the challenger to which voter $i$ is the closest. This happens in two out of seven municipalities, while the remaining five elections have two candidates.
} 
group), specifically whether voters closer in policy space to the incumbent tend to vote more for him. The coefficient of interest is $\delta^{2}$, measuring the degree to which the informational treatment increases the effect of policy promises on vote choice. For instance, $\delta^{2}>0$ may be the result of voters in fact learning about the campaign promises, updating their beliefs, and employing this information in their decision making process. Alternatively, $\delta^{2}>0$ may be the result of voters becoming aware of the role of mayors in public goods provision, made salient by our treatment, therefore discriminating among candidates based on policy platforms. Or both mechanisms may be at play. Equation (3), like most reduced-form settings, cannot discriminate between learning and salience, nor quantify their relative weight in explaining individual decisions, as both mechanisms would operate through changes in $\delta^{2}$.

Consistent with the model discussed in Section 2, voters with information about candidate promises are more likely to vote for the candidate whose promises are closest to them in the policy space (Panel A of Table 1). Based on the estimates of $\delta^{2}$, a one standard deviation increase in the measure of $\Delta$ Similarity increases the likelihood of voting for the incumbent by 3-4 percentage points. This is a noticeable effect given that the control group mean of the outcome variable is 68.9 percent. This is true whether we restrict the similarity measures to the voter's preferred sector (Column 1), two preferred sectors (Column 2) or three preferred sectors (Column 3). We find similar results if we only look at similarity for health, education and agriculture assistance (Column 4) or for the 10 sectors jointly (Column 5).

The effects tend to be stronger for T1 than for T2 (Panel B of Table 1). Recall that in T1 voters are only provided with information on promises made by candidates in the 2016 elections, whereas T2 voters are also provided with information on promises made in 2013. While we cannot reject the null that the effects are similar for T1 and T2, the point estimates for $\mathrm{T} 1$ tend to be larger than the point estimates for T2. Only the point estimates for T1 are consistently significant and precisely estimated. We examine these issues further below.

There is one potential consideration about these results. ${ }^{22}$ In addition to belief updating $f^{i, j}\left(\mathbf{p}_{j} \mid h\right)$ and changes in preference weights $\left\{\alpha_{i}, \gamma_{i}, \omega_{i}\right\}$ due to salience, treated voters might have adjusted their ideal points $\mathbf{q}_{i}$ to match the promises of their preferred candidate. We can test for this additional channel directly, as we know which candidate respondents voted

\footnotetext{
${ }^{22}$ We also provide evidence that allows us to rule out large SUTVA violations as discussed in Section 2. We get a measure of potential information diffusion between treatment and control barangays and show that outcomes of interest do not differ between control villages that are well connected to treated villages and control villages that are not as well connected to treated villages. In the 2013 survey all respondents were asked to list (up to 10) barangays in their municipality where their family/friends reside. We use this information to proxy for information flows between the villages. In particular, for each pair of barangays $(a / b)$ we can count the number of times $a$ is cited by individuals living in $b$ and the number of times $b$ is cited by individuals living in $a$. For each control group barangay, we then count the total number of links between the barangay a and all treated barangays in the municipality. We then create a dummy equal to one for barangays that are more connected to treated barangays (above the median number of links). If spillovers are present we expect the diffusion of information to be larger in barangays that are more connected to treated barangays. To get a rough sense of the presence of spillovers we regress our outcomes of interest for the control group on a set of municipal fixed effects and our dummy variable. The results available in Tables A.10 and A.11 rule out large SUTVA violations.
} 
for and we elicit ideal points directly. We do not find any evidence that the treatment increase voter's closeness to their preferred candidate. This is true whether we compute similarity in terms of the distance between voter ideal points and stated candidates (Table A.12) or between voter ideal points and voter's beliefs about what candidates will do if elected (Table A.13). In addition, we run regressions where we separately control for similarity between voter/incumbent and for similarity between voter/challenger. The point estimates are of similar magnitude, but of opposite signs (Table A.14). Again, this suggests that our results are not solely driven by voters adjusting the preferences to match those of their preferred candidate.

Why do voters respond to the treatment? As discussed in Section 2, in addition to collecting data on the mode of posterior beliefs, we asked respondents to indicate their overall degree of certainty over all allocations (Q2). This information is useful not just for the structural analysis that follows, but also in itself. We find that treated voters are more certain (Table 2 ) and especially in the case of voters treated with T1. There is also evidence that voters are indeed better informed upon treatment. We can compute the distance between candidate promises and voter's beliefs about what the incumbent will do if elected, represented in

our notation as $\left\|\phi_{j}-\pi_{i, j}\right\|$. This distance tends to be systematically lower in treated villages (Table 3). Again, consistent with the previous set of results, treatment effects on certainty and information tend to be stronger for T1 than for T2.

These findings provide some direct evidence of an effect of our treatments through subjective beliefs, which we have just shown change relative to control voters both in terms of variance and in terms of accuracy. The structural model in Section 5 will further demonstrate whether these effects are substantial in terms of reduction of the overall dispersion of beliefs and whether information in campaigns operates only through belief updating or also through salience.

\subsection{Voters who are reminded of past promises reward incumbents who fulfilled them}

We now turn our attention to explaining why the effects discussed so far appear to be stronger for T1 than for T2. Recall that voters in T2 were informed both about the promises of 2016 candidates and with the promises that past candidates made in 2013. That is, using information available to them, voters can assess whether the incumbent fulfilled his promises between 2013-2016. We can test whether they behave this way by estimating equations of the form:

$$
Y_{i v l}=\alpha T_{v l}+\beta K e p t_{v l}+\gamma T_{v l} \times K e p t_{v l}+v_{l}+u_{i v l}
$$


where $\mathrm{Kept}_{v l}$ is a dummy equal to one if the incumbent fulfilled her 2013 promises. ${ }^{23}$ As before, all regressions include a full set of triplet fixed effects and the standard errors are clustered at the village-level. We are interested in $\gamma$. If voters care about incumbents fulfilling their promises, $\gamma$ should be greater than zero. To account for the potential differences between $\mathrm{T} 1$ and $\mathrm{T} 2$ we also estimate those effects separately.

Treated voters are more likely to vote for the incumbent when she fulfilled past promises (Column 1 of Table 4). The entire effect comes from T2: the point estimate for T2×Kept is 0.13 while it is only -0.0025 for T1×Kept (Column 2 of Table 4 ). ${ }^{24}$ This effect is very large and is consistent with the notion that voters care strongly about incumbent's ability to fulfill their promises. The point estimates on $\mathrm{T} 2$ is -0.015 , which suggests that voters penalize candidates that do not fulfill their promises $($ Kept $=0)$. However, these estimates are noisy and we are unable to reject the null of no effect. These results are not merely capturing the fact that the mayor allocated more projects to a village, as they are robust to controlling for the number of projects provided by the mayor during her term and its interaction with the treatment dummies (Table A.16).

The effects of T2 for incumbents who fulfilled their promises appear to work through valence beliefs. We can estimate equation (4) but replace $Y_{i v l}$ with respondent's beliefs about incumbent valence along all different dimensions. In villages where the incumbent fulfilled her promises voters who received information about the earlier 2013 promises were more likely to rate her as honest and capable (Table 5). These are the two valence dimensions conceptually closest to keeping one's promises. No other valence dimension is precisely affected. These results are again robust to controlling for the number of projects provided by the mayor during her term and its interaction with the treatment dummies (Table A.17).

\subsection{Voters that are not part of clientelist networks respond more to the treatment}

As a check on the reliability of our results, we explore heterogeneity in how voters respond to the treatment. In particular, given the clientelist nature of politics in the Philippines, we distinguish between voters who have easy access to clientelist goods and those who do not. clientelist voters are the ones who have the most to lose by switching to programmatic voting and we expect them to respond less to the treatment.

As described in Section 3, we identify clients as those who can easily ask politicians to pay for their medical expenses (typically based on some predetermined characteristic, such as family ties) and estimate equation (3), but estimate $\gamma$ separately for clients and non-clients. In Table 6 we show that non-clients, defined as those who are unable to easily ask politicians

\footnotetext{
${ }^{23}$ In those regressions we drop the municipality of Bangui as Diosdado Garvida, the mayor elected in 2013, was suspended from his post halfway into his term.

${ }^{24}$ Importantly, this set of results is robust to controlling for our similarity measures and their interactions with the two treatments. Those results are available in Table A.15. The point estimates on both $\mathrm{T} 1 \times \Delta$ Similarity and $\mathrm{T} 2 \times$ Kept are very stable and we can comfortably reject the null of no effects.
} 
to pay for medical expenses, respond strongly to the treatment. Clients respond more weakly to the treatment. In Appendix, we show that our results hold if we measure clientelism with the ease with which the respondent can obtain an endorsement letter for a job (Table A.18) or can obtain support to pay for funeral expenses (Table A.19). Similarly, we obtain consistent results if we look at whether the respondent has a political link to the mayor (Table A.20).

\section{Structural Estimation}

Section 4 has offered an intuitive representation of several empirical causal relationships at work in our setting. The structural model in this Section organizes such relationships in a unified econometric environment. We begin by reporting the results of the estimation of the empirical model from Section 2 and two specification selection tests.

Table 7 presents maximum likelihood estimates for a basic random utility model of vote choice where preference parameters are restricted to be the same across treated and control voters. That is, we impose for any $i\left\{\alpha_{i}, \gamma_{i}, \omega_{i}\right\}=\{\alpha, \gamma, \omega\}$. The specification corresponds to a standard choice environment of the type analyzed by Kendall et al. (2015), where any role for salience is excluded. As is standard in these environments, the units of measurement for the parameters are expressed in terms of standard deviations of the random utility shock $\varepsilon_{i j}$. To keep the dimensionality of the problem tractable in the structural estimation, we perform our analysis on $K=4$, with health, education, agricultural assistance (the three largest expenditure categories), and a residual (other) category.

The model exhibits a precise estimate of 0.37 for preference weights on clientelist transfers $\alpha$, where $z_{i}$ is approximated by an indicator of whether $i$ has a predetermined patron-client tie to the incumbent in the form of family or personal friendship connections. Interestingly, valence parameters $\gamma$ (representing a vector of weights on the incumbent ranking higher in approachability, experience, honesty, connections, competence, and empathy) are typically larger in magnitude than $\alpha$ and precisely estimated (we estimate $\gamma_{1}=1.54$, approachability, three times larger, and only $\gamma_{4}=0.13$, politician's connections, is smaller). This holds across specifications, with valence beliefs representing the most significant driver of vote choice across all municipalities. Policies matter, however, as one would have anticipated from Section 4, with a weight $\omega=0.71$ and an asymptotic standard error of $0.22 .^{25}$

In line with previous evidence in Kendall et al. (2015), the loss function coefficient $\zeta$ is estimated to be statistically below $1(0.22$, s.e. 0.05$)$. Recall that $\zeta$ indicates the parameter governing the p-norm defining spatial preferences. We thus reject convex loss functions (commonly assumed in the literature, for instance in the form of quadratic losses) and present evidence in favor of voters being more sensitive to differences around their ideal points than to policy differences occurring far away from their ideal points. This finding,

\footnotetext{
${ }^{25}$ Asymptotic standard errors are computed by Outer Product of Gradients.
} 
once again, alerts us against operating under the analytically convenient, but apparently empirically counterfactual, assumption of purely convex losses. ${ }^{26}$

Parameters governing the probability mass on the mode for individual beliefs, $\psi$ (3) for rather uncertain and $\psi(2)$ for very uncertain, are imprecise.

Finally, we verify that the Ramalho and Smith correction for the "missing completely at random" (MCAR) violation is in fact necessary. We obtain statistically different parameters for the probability of nonresponse for supporters of incumbent candidates (0.03) versus the probability of nonresponse for supporters of challengers (0.13). Incumbents in the Philippines are typically at an electoral advantage and the evidence validates the concern that voters may shy away from explicitly stating their support of challengers in these races.

Table 8 extends the empirical analysis to voters' psychological response to the treatments, in the form of salience. We define salience effects (also indicated as awareness effects in the literature) as the causal effects of informational treatments on preference weights on transfers, valence, and public policy weights in voters' utility functions, $\left\{\alpha_{i}, \gamma_{i}, \omega_{i}\right\}$. These effects do not operate through subjective beliefs, but are akin to state-dependent preferences.

Salience effects are substantial on important margins. Voters made aware of policy platforms by either T1 or T2 (both treatments include candidate platform information, making policy salient) increase voters' weight on policy $\omega$ from 0.71 to 0.99 and reduce the weight $\alpha$ placed on clientelist transfers from 0.37 to 0.28 . This finding is important: policy information in our flyers, by raising awareness and increasing policy salience, appear to affect voters' decision making, inducing them to place higher weight on programmatic politics as opposed to clientelist handouts. This policy enhancement effect is identified in practice by comparing two voters with identical beliefs, but one in the control and the other in the treatment group and verifying that the treated individual places more weight on public policy when voting. Importantly, this happens regardless of the amount of learning, which below we also show is quantitatively relevant in terms of changing second moments of voters' beliefs.

Parameters governing the probability mass on the mode for individual beliefs, $\psi$ (3) for rather uncertain and $\psi(2)$ for very uncertain, are now precisely estimated. All valence dimensions weights remain precisely estimated and valence maintains an important role in explaining vote choice. The Ramalho and Smith correction for the MCAR violation appears necessary under this specification as well.

The model allowing for salience effects of Table 8 can be statistically tested against the restricted model of Table 7, where preferences are not allowed to respond to treatment. A Likelihood Ratio test supports the salience model. The two log likelihoods indicate a superior fit of the salience and a likelihood ratio test statistic favors the salience model specification relative to the restricted specification with a $\chi^{2}(7) \mathrm{p}$-value of 0.038 .

\footnotetext{
${ }^{26}$ Given estimate of $\zeta$ below 2, we also checked the robustness of our reduced form analysis to a measure of similarity allowing for concavity in losses $(\zeta=.2)$. We found our reduced-form results qualitatively robust to this correction.
} 
Table 9 finally allows for voter psychological responses to our treatments in the form of salience, but imposes $\omega^{0}=0$, that is no weight on policy for the control group. This approach assuages the concern that control voters may induce inconsistency in the estimation through their policy-related parameters $\omega^{0}, \zeta, \psi(2), \psi(3)$. To see how this would induce problems of inference, consider as a form of misspecification the case of control group voters so completely unaware of policy as to not even have properly defined beliefs or preferences over it. No information from the control voters should therefore be used to estimate of policy or beliefs parameters. In Table 9 we eliminate this issue by excluding any role for policy for the control and find estimates consistent with Table 8 for all parameters shared across the two models. The results from Table 8, therefore, appear robust to this potential misspecification problem. In addition, a Vuong test for non-nested model selection of Table 9 salience specification again supports the presence of salience effects relative to the specification of Table 7 at standard confidence levels.

While the maximum likelihood estimates reported in Table 8 are informative about the effect of treatment on preferences and indicate precise parameters for both beliefs and preferences in the treated sample, they are not informative about the tightening of the posterior beliefs that occurs due to rational learning. We know from the reduced-form analysis of Table 2 that voters become more certain about candidate policies upon receiving our informational treatments. Their beliefs become also more accurate. However, the dispersion of their beliefs about multiple candidates and policy dimensions should be estimated through the modelestimated variance-covariance matrices associated with individual subjective beliefs. Such beliefs depend on which policy dimensions voters are most uncertain about and on where each multivariate distribution locates the bulk of its mass on the simplex (as indicated in Section 2.3). Beliefs, for example, may be highly asymmetrical for incumbents and challengers and display very different second moments, skewness, etc. even for identical levels of certainty as per $Q 2{ }^{27}$

The variance-covariance matrices of beliefs generated based on survey answers to $Q 1, Q 2, Q 3$ and estimates of $\psi(2), \psi(3)$, show lower dispersion for the treated voters than for control voters. That is, the estimated variance-covariance matrix of beliefs of voters are generally tighter for treated than for control voters and the difference between these two matrices is positive semi-definite. The intuition that posterior beliefs should tighter in terms of dispersion than priors in the presence of rational learning is appropriate for a large class of learning models and we find evidence of it in most municipalities. At the same time, it is relevant to emphasize that it is possible to construct theoretical cases where more information increases posterior dispersion, for instance by confusing voters who are initially certain.

The procedure we follow to assess variance-covariance matrices involves four steps. We

\footnotetext{
${ }^{27}$ In essence, it is not sufficient to simply rely on survey answers to $Q 2$ or $Q 3$ individually or to look at the relative positions indicated by the modes in $Q 1$. Rather, this information has to be jointly assessed within the structure of the model.
} 
first calculate the estimated variance-covariance matrix of beliefs for all voters about the candidates under their consideration. We then average the variance-covariance matrices for all voters within T1, T2, or $\mathrm{C}$. We then take the element by element difference of the average variance-covariance matrix for the Control group and the variance-covariance matrix for each Treatment arm and compute its value in standard deviation units of the corresponding element average variance-covariance matrix for the Control group. We report the diagonal elements of the resulting matrix.

In terms of overall reduction of second moments of individual beliefs, averaging across all policies, all municipalities, and all voters relative to the Control group, Treatment 1 reduces belief dispersion by 13.2 percent of the Control standard deviation level, while Treatment 2 reduces the standard deviation by 11.5 percent based on the model estimated belief distributions for the incumbent (results for the challenger are quantitatively and qualitatively similar). In the municipalities of Bangui, Burgos, Paoay, San Juan, Pasuquin second moments contracted as result of the experiment, while in Dingras and Lidlidda our treatment increased dispersion. We do not observe systematic asymmetry in terms of variance reductions for challenger and incumbents, possibly related to the paucity of information about all candidates, as discussed above.

San Juan, Paoay and Pasuquin are the municipalities where the informational effects appear the strongest in terms of second moments. To the reader interested in the reductions by each treatment arm, municipality, policy category (limiting the analysis to health, education, agricultural assistance, and a residual "other" category) for the incumbent, we report them in Table 10. As can be seen in the table, belief tightening along each dimension is not due to a single outlier municipality, a specific candidate, or an influential policy dimension. It occurs fairly homogeneously across all categories and the variance reduction appears stronger for T1 rather than T2 (consistent with the reduced-form evidence presented in the previous section). The evidence therefore supports the view that a substantial amount of learning about policy, in addition to the increase salience documented above, occurs in this context.

\subsection{Model Fit}

The in-sample fit of the model is good, as reported for each municipality in Table 11. All actual municipal election winners are correctly predicted by the model.

In terms of fit of individual voter choices, we capture well above sixty percent of individual vote choices in most municipalities. In Dingras and San Juan we predict correctly over 90 percent of individual choices. Lidlidda, Pasuquin and Burgos also have correct predictions between 61 and 76 percent. There are two municipalities where the fit is less good: Paoay and Bangui. In Paoay the race was extremely close (and the incumbent eventually lost) and many individual choices appear fairly close in terms of expected utility between challenger and incumbent. It was, in essence, a difficult race to predict. In Bangui, a less accurate fit had 
to be expected, as Diosdado Garvida, the mayor elected in 2013, was in fact suspended and removed from his post in the middle of his term on charges of corruption. He was replaced by his deputy, who then run in 2016.

For the out-of-sample fit assessments in Table 11, we perform a leave-one-out predictive exercise. We estimate the model for six municipalities at a time and then predict vote decisions based on the estimated parameters for the remaining (seventh) municipality. Table 11 reports the correct votes proportions for this out-of-sample exercise. Importantly, the model's performance remains solid and, remarkably, it appears of equivalent quality as the in-sample fit. This robustness in fit not only confirms the predictive value of our framework, but provides reassurance about the stability of the structural estimates across the various municipalities. Our results do not appear driven by a specifically influential or larger municipality; they are stable across sub-samples of municipalities, and useful for prediction in this context.

\subsection{Counterfactual Exercises}

We present four counterfactual exercises in Table 12. The choice of incumbent vote shares as the main outcome variable of interest is driven by our emphasis on assessing the relevance of the various components of voting behavior we have modeled on a political dimension of immediate importance (i.e. the key outcome for incumbent and potential challengers) and also for its usefulness in expanding the discussion to issues of incumbency advantage and political encroachment, which are typical of the political environment that we study.

We consider first a counterfactual election where vote-buying is excluded from voters' utility. Conversely, one can think of a perfectly clean election where $z_{i j}=0 \forall i, j$. This can be implemented within our analysis by setting $\alpha=0$, making voters insensitive to clientelist ties or eliminating such ties altogether. Under this counterfactual, one out of seven elections in our sample would have changed its final outcome (in the municipality of Lidlidda) and across all municipalities vote shares for the incumbent would fall by 1 to 3 percentage points. This indicates that vote buying is important, but far from the only determinant of voter support for candidates in the Philippines.

To see this, we can study a counterfactual election where only vote buying matters for voters $\left(\gamma_{i}=0 ; \omega_{i}=0 \forall i\right)$. Were only clientelist ties at play, our model would explain a fairly low share of vote choices, as evident in Table 12. In fact, our third counterfactual, the model where only the valence and policy dimension is politically active displays a much larger quantitative power than vote buying alone.

In a third counterfactual we assess the gain in vote share for the incumbent in the presence of an increase in awareness about public policy. We perform this by imposing for any voter $i$ utility weight on policy $\omega_{i}=\omega^{0}+\omega^{1}$ independently of treatment or control status and without changing posteriors. We use the salience-enhanced policy weight estimated for the 
treatment group in Table 8 for every voter, including control. As can be seen, this in itself has no effect on incumbent vote shares, as this policy counterfactual does not have an a priori bias in favor of the incumbent or of the challenger. But this also underlies a lack of private incentives to make voters aware of policy issues on the part of any candidate, an issue that we expand in detail in the following Section.

Finally, we consider an election where the incumbent announces a policy platform that sets voters' beliefs mode at the geometric median of the voters policy preference space (i.e. the generalized median of the set of ideal points $\left\{\mathbf{q}_{i}\right\}_{i=1}^{N}$ ). We keep the modes constant for the challenger. For general theoretical environments with multidimensional policy competition between two candidates there is no theoretical guarantee of convergence to the generalized median voter position, so this example should be considered more illustrative of the potential of the model in quantifying electoral effects of realistic informational campaigns. This electoral campaign counterfactual would appear prima facie productive for the incumbent in terms of increase in electoral support. However, incumbent and challenger both locate sufficiently close to the geometric median that the average adjustment for each policy dimension across all municipalities is only about $5 \%$ budget share for the incumbent $(6 \%$ for the challenger). In addition, due to the high curvature of the loss function when close to the ideal point of voters, even small policy adjustments may alienate as many voters as they please. Across all municipalities, these effects seem to balance and incumbent vote shares appear essentially unaffected.

\section{Cost Effectiveness}

Our results highlight an important puzzle: if information about policies can be effective in changing voter evaluations of candidates, why don't candidates use policy information as a campaign strategy? Why do mayoral candidates engage in vote buying and clientelist practices instead?

It is certainly not for lack of information about the relative merits of different electoral strategies-interviews with Philippine mayoral candidates suggest that they assess costs and electoral gains in sophisticated ways. ${ }^{28}$ Given that Philippine mayors are sophisticated political actors and distributing fliers with policy information is relatively straightforward, why has it not occurred to them to publicize policy information for electoral gain?

Our field experiment and the analysis above provide us with accurate per-vote cost estimates for implementing the information campaign in this context. In this Section we also use additional survey data and unique data sources in order to collect similar information

\footnotetext{
${ }^{28}$ For example, one candidate we interviewed had a spreadsheet tracking allocation of funds for vote buying for the different villages in the municipality. Other candidates explained cost-saving measures that they have taken: engaging in wholesale vote buying to target identifiable groups, or collaborating with provincial and national level candidates to pool vote buying money to purchase a single slate of votes.
} 
on the range of price per vote for vote buying. This allows us to offer a comparison of costs between the two different electoral strategies. ${ }^{29}$

Distributing fliers to treatment villages within a municipality costs $\$ 5,700$ (current USD) on average, or about \$3-\$5 per flier. This amount includes all costs of collecting policy data from candidates, professionally printing the fliers, training enumerators about the fliers, and hand-delivering fliers to households. ${ }^{30}$

These are non-trivial costs for a country like the Philippines where income per capita in 2016 was $\$ 2,951$ (according to the World Bank). However, compared to the average cost of running for mayor (as reported by candidates) in the 2016 elections, distribution of fliers is significantly less expensive. According to mayoral candidates, the average amount needed to run for mayor was $\$ 38,550,{ }^{31}$ almost six times higher than our informational treatment costs. This difference in scale reinforces the puzzle of why mayors do not use informationbased campaign strategies, given that the campaign budgets could certainly accommodate it in terms of magnitudes.

An analysis of the electoral returns of the different political tools sheds more light on how to interpret these differences. According to our household survey data, conditional on having received any money for their vote, the average amount given to voters was $\$ 31$ (removing the top percentile of reported amounts, the average amount drops to \$22). ${ }^{32}$ Price per vote varies by municipality, often as a function of local economic conditions, but is generally in the range of $\$ 20-\$ 50$ per household for local elections across municipalities in our study area. ${ }^{33}$

At the high bound of the range and assuming that votes are delivered, the per vote cost of vote buying reaches $\$ 12.50$ (i.e. at $\$ 50$ per household, considering 4 people on average per household). These are reasonable assumptions, as vote buying is commonly known

\footnotetext{
${ }^{29}$ Note that we do not need to assume that candidates coordinate around the release of policy information. Suppose a voter is deciding whether to vote for candidate $A$ or $B$. Voters have priors about what the candidates will do. Let's assume that candidate $A$ provide some information about herself and/or her programs. Voters will then update their beliefs about both candidates (including from the fact that $B$ is not responding if she isn't). Then voters can decide which candidate to vote for. Such a game can have a symmetric equilibrium where both candidates disclose or asymmetric ones where only one discloses.

${ }^{30}$ Note that our flyers were delivered in partnership with a credible non-partisan organization, while politicians may face additional challenges or costs when delivering information through their campaign or coordinating an information campaign with the other candidates.

${ }^{31}$ Note that these figures are taken from the survey question asking about the general cost for running for mayor in their municipality; by contrast, candidates tended to report that their own campaign expenditures were less.

${ }^{32}$ While the survey data are noisy, the averages are broadly in line with the ranges given to us by key informants in separate interviews. The conversion USD/PHP at May 9, 2016 exchange rate (election day)

${ }^{33}$ We received permission from the bishops and archbishops of the Archdiocese of Nueva Segovia to collect vote buying data from semi-structured interviews with parish priests in Ilocos Norte and Ilocos Sur. Because priests are in a position to obtain sensitive information given their central role in their community, we collected information only about general trends or averages in their parishes. We did not collect any information about specific individuals, such as which individuals received illegal payment or how much certain individuals received - information to which priests have access through confessions. We used preliminary information from these additional surveys of parish priests in order to verify the price data that we received from both the surveys and the mayors.
} 
to be enforceable in the Philippines. ${ }^{34}$ Even so, we use the high end of the vote buying range in order to account for these additional monitoring and logistical costs associated with vote buying, assuming that they can be included in higher prices per vote, as in figure 2. Furthermore, we are documenting common features of vote buying that are not limited to the Philippine context-a broad literature covers the mechanics of vote buying across a number of other countries: (i) including aggregate methods of monitoring both brokers (Larreguy, 2013; Larreguy et al., 2016; Bowles et al., 2017) and voters (Rueda, 2017); (ii) targeting vote buying based on personal connections (Stokes, 2005; Szwarcberg, 2014) and individual characteristics such as reciprocity (Finan and Schechter, 2012; Lawson and Greene, 2014) and social persuasion (Lehoucq, 2007; Schaffer and Baker, 2015); or (iii) using forms of vote buying that require less monitoring (Schaffer and Schedler, 2007; Nichter, 2008).

The rationale for why buying votes may be electorally appealing becomes apparent at this point. Assume that candidates can micro-target our information treatments exactly to the subset of voters whose policy interests are aligned with them and produce a one standard deviation shift in similarity along the policy dimension. Based on our estimates from Section 4, we obtain that a one standard deviation increase in similarity yields an additional vote share of 4 percent. Treating 100 households (about 400 people) at $\$ 5$ per flier produces an expenditure of $\$ 500$ and yields 16 votes. This implies a per vote cost of information of $\$ 31.25$ per vote, or about 2.5 the cost of buying a vote. Even assuming that only 1 in 2 votes is delivered when bought, the informational treatments falls behind vote buying in terms of electoral returns. ${ }^{35}$

In fact, as illustrated in Figure 2, even at compliance rates well outside the normal range for the Philippines, vote buying is still the more cost-effective electoral strategy. ${ }^{36}$ Vote buying only becomes less cost effective when both lack of compliance and price per vote approach unrealistic levels. At the same time, even though these prices are well outside the normal range for vote buying, vote buying is still a comparatively more cost-efficient strategy as long as compliance rates are above $80 \%-85 \%$. Furthermore, the price per vote and compliance rates are positively correlated, making it even more unlikely that we would observe high prices per vote and low compliance rates. Survey data on vote prices suggest

\footnotetext{
${ }^{34}$ Politicians and brokers use a wide range of strategies for ensuring that voters vote accordingly. The most straightforward are direct means of violating ballot secrecy, such as removing the discretion of voters by providing pre-filled ballots or requiring proof of vote choice (Cruz, 2013). Examples include instructing voters to mark the ballot in a certain way, or use cell phone pictures or carbon paper to record the markings made on the ballot.In the Philippines, these direct methods are less common (survey data indicates that less than $20 \%$ of voters targeted for vote buying report having to provide proof of their vote). Philippine brokers prefer to target voter buying to individuals that do not need to be monitored, either because of adherence to norms of reciprocity or the use of indirect monitoring through voter social networks (Cruz, 2013).

${ }^{35} \mathrm{~A}$ low compliance rate, considering that compliance with vote buying ranges from $70 \%$ at the low end to $100 \%$ at the high end, according to conversations with local political intermediaries who discussed the matter anonymously.

${ }^{36}$ The examples are based on the average municipality in our sample and average number of adults per household.
} 
that politicians are more likely to use monitoring methods in areas where the price per vote is higher, a relationship that is confirmed by interviews with political operatives.

We believe that this analysis speaks to the mechanisms behind the under-provision of political information in consolidating democracies. The gap between information campaigns and clientelist electoral strategies highlights a valid rationale for the absence of policy content in these regimes. Even if campaign information on policy is effective, as we have shown, this does not subtract from the fact that for politicians vote buying is more cost-effective. A lack of engagement in programmatic discourse and absence of information dissemination follows from this calculation. In terms of policy implications, this analysis suggests a possible role of free media and non-governmental organizations to provide this information in places where the private electoral incentives of politicians may be insufficient.

\section{Conclusion}

In many democracies in the developing world, providing public goods and implementing policy programs are simply not effective strategies for winning elections. We argue that in addition to focusing on development and economic policy innovations, it is important to understand the features of the political context that make it difficult for politicians to pursue growth-friendly policies to begin with. We build on previous experimental research that has attempted to address the informational deficiencies of voters in these democracies, by using a new field experiment to provide voters with some of the information they need to evaluate their candidates on both policy and valence dimensions.

This paper presents an empirical model of voting in emerging democracies. These are political environments where clientelism and vote buying are the primary modes of electioneering, but voters still use information in rational ways and update their beliefs accordingly. We show that preferences over candidates follow standard spatial voting theory. Voters

given information about candidate platforms prefer candidates whose budgetary allocations are closest to their ideal points. Furthermore, we show that the electoral effect of information treatments is substantial. Voters use political information in rational ways and update their subjective beliefs along both policy and valence dimensions.

Voters respond to different types of information in sophisticated ways, suggesting that even simple information interventions can be effective. While these findings may be surprising to researchers interested in voting in less than consolidated democracies - a literature that occasionally takes a more behavioral perspective - further analysis about the role of informational treatments and rational updating may be relevant to the study of democratic consolidation. Future research should address more precisely whether salience of public goods provision and cueing on programmatic politics may induce quantitatively relevant electoral effects. 
We also show one path towards increasingly programmatic and policy-based political discourse. Our new cost-benefit analysis comparing vote buying to policy-based interventions shows that for candidates, vote buying is a more cost-effective electoral strategy. This suggests a possible role for non-governmental or media organizations to provide this type of policy information absent politician incentives to do so. It also suggests that one possible way for incentivizing politicians to pursue policy-based strategies is to increase the targeting or monitoring costs of vote buying, thus decreasing the compliance rate and making it a less efficient strategy. These efforts can take relatively simple forms-procedural changes to improve voter privacy when casting ballots and additional safeguards to ensure ballot secrecy. The formal quantitative approach followed in this paper can help in calibrating them more precisely. 


\section{References}

Achen, Christopher H. and Larry M. Bartels, "Blind Retrospection Electoral Responses to Drought, Flu, and Shark Attacks," June 2004. Estudio Working Paper 2004/199.

Ansolabehere, Stephen and Philip Edward Jones, "Constituents' Responses to Congressional Roll-Call Voting," American Journal of Political Science, 2010, 54 (4), 583-597.

— , James M. Snyder, and Charles Stewart III, "Candidate Positioning in U.S. House Elections," American Journal of Political Science, 2001, 45 (1), 136-159.

Aragones, Enriqueta, Thomas Palfrey, and Andrew Postlewaite, "Political Reputations and Campaign Promises," Journal of the European Economic Association, 2007, 5 (4), 846-884.

Arias, Eric, Horacio Larreguy, John Marshall, and Pablo Querubin, "Priors Rule: When do Malfeasance Revelations Help or Hurt Incumbent Parties?," 2018.

Banerjee, Abhijit, Esther Duflo, Clement Imbert, and Rohini Pande, "Entry, Exit and Candidate Selection: Evidence from India," MIT, mimeo, 2018.

_ , Selvan Kumar, Rohini Pande, and Felix Su, "Do Informed Voters Make Better Choices? Experiment Evidence from Urban India," MIT, mimeo, 2011.

Bennett, W. Lance and Shanto Iyengar, "A New Era of Minimal Effects? The Changing Foundations of Political Communication," Journal of Communication, 2008, 58, 707-731.

Bernhardt, Dan, Odilon Camara, and Francesco Squintani, "Competence and Ideology," Review of Economic Studies, 2011, 78 (2), 487-522.

Bidner, Chris and Patrick Francois, "The Emergence of Political Accountability," The Quarterly Journal of Economics, 2013, 128, 1397-1448.

_ , _ , and Francesco Trebbi, "A Theory of Minimalist Democracy," NBER WP 20552, 2014.

Bidwell, Kelly, Katherine Casey, and Rachel Glennerster, "Debates: The Impact of Voter Knowlegde Initiaties in Sierra Leone," Research Papers, Stanford University, Graduate School of Business 2015.

Bischof, Daniel, “New Graphic Schemes for Stata: plotplain and plottig," Stata Journal, 2017.

Bowles, Jeremy, Horacio Larreguy, and Shelley Liu, "Exploiting Weakness in Electoral Administration: Monitoring Brokers in a Developing Democracy," 2017.

Brierley, Sarah, Eric Kramon, and George Ofosu, "The Moderating Effect of Debates on Political Attitudes," Technical Report 2018. 
Callander, Steven and Simon Wilkie, “Games and Economic Behavior,” 2007, 60, 262-286.

Capuno, Joseph, "The PIPER Forum on 20 Years of Fiscal Decentralization: A Synthesis," Philippine Review of Economics, 2012, 49 (1), 191-202.

Chappell, Henry W. Jr., "Campaign Advertising and Political Ambiguity," Public Choice, 1994, 79 (3-4), 281-303.

Chong, Albert, Ana Lorena De La O, Dean Karlan, and Leonard Wantchekon, "Does Corruption Information Inspire the Fight or Quash the Hope? A Field Experiment in Mexico on Voter Turnout, Choice and Party Identification," Journal of Politics, 2015, 77, 55-71.

Cruz, Cesi, "Social Networks and the Targeting of Vote Buying," Annual Meeting of the American Political Science Association, 2013.

- and Christina J. Schneider, "Foreign Aid and Undeserved Credit Claiming," American Journal of Political Science, 2017, 61 (2), 396-408.

_ , Philip Keefer, and Julien Labonne, "Buying Informed Voters: New Effects of Information on Voters and Candidates," mimeo, 2018.

DellaVigna, Stefano and Matthew Gentzkow, "Persuasion: Empirical Evidence," Annual Review of Economics, 2010, 2, 643-669.

Downs, A., An Economic Theory of Democracy, Harper Row, 1957.

Dunning, Thad, Guy Grossman, Macartan Humphreys, Susan Hyde, and Craig McIntosh, Metaketa I: The Limits of Electoral Accountability, Cambridge University Press, forthcoming.

Ferraz, Claudio and Frederico Finan, "Exposing Corrupt Politicians: The Effects of Brazil's Publicly Released Audits on Electoral Outcomes," The Quarterly Journal of Economics, 2008, 123 (2), 703-745.

Finan, Frederico and Laura Schechter, "Vote Buying and Reciprocity," Econometrica, 2012, $80(2), 863-881$.

Fujiwara, Thomas and Leonard Wantchekon, "Can Informed Public Deliberation Overcome Clientelism? Experimental Evidence from Benin," American Economic Journal: Applied Economics, 2013, 5 (4), 241-255.

Garthwaite, Paul H, Joseph B Kadane, and Anthony O'Hagan, "Statistical Methods for Eliciting Probability Distributions," Journal of the American Statistical Association, 2012, 100, 680-701. 
Gottlieb, Jessica, "Greater Expectations: A Field Experiment to Improve Accountability in Mali," American Journal of Political Science, 2014, 60, 143-157.

Grimmer, Justin, Solomon Messing, and Sean J. Westwood, "How Words and Money Cultivate a Personal Vote: The Effect of Legislator Credit Claiming on Constituent Credit Allocation," American Political Science Review, 2012, 106 (4), 704-719.

Hicken, Allen, Stephen Leider, Nico Ravanilla, and Dean Yang, "Measuring Vote-Selling: Field Evidence from the Philippines," American Economic Review PEP, May 2015, 105 (5), $352-56$.

Humphreys, Macartan and Jerey Weinstein, "Policing Politicians: Citizen Empowerment and Political Accountability in Uganda - Preliminary Analysis," Working Paper, International Growth Center, 2013.

Hutchcroft, Paul and Joel Rocamora, "Strong Demands and Weak Institutions: The Origins and Evolution of the Democratic Deficit in the Philippines," Journal of East Asian Studies, 2003, 3 (2), 259-292.

Kadane, Joseph B. and Lara J. Wolfson, "Experiences in Elicitation," Journal of the Royal Statistical Society. Series D (The Statistician), 1998, 47 (1), 3-19.

Keefer, Philip and Razvan Vlaicu, "Vote buying and campaign promises," Journal of Comparative Economics, 2017, 45 (4), 773-792.

Kendall, Chad, Tommaso Nannicini, and Francesco Trebbi, "How Do Voters Respond to Information? Evidence from a Randomized Campaign," American Economic Review, January 2015, 105 (1), 322-53.

Kerkvliet, Benedict J.T., Everyday Politics in the Philippines. Class and Status Relations in a Central Luzon Village, Rowman and Littlefied Publishers, 2002.

Khemani, Stuti, “Buying Votes vs. Supplying Public Services: Political Incentives to UnderInvest in Pro-Poor Policies," Journal of Development Economics, 2015, 117, 84-93.

Klapper, Joseph T., The effects of mass communication, New York, NY, US: Free Press, 1960.

Labonne, Julien, "The Local Electoral Impacts of Conditional Cash Transfers: Evidence from the Philippines," Journal of Development Economics, 2013, 104, 73-88.

- , "Local Political Business Cycles. Evidence from Philippine Municipalities," Journal of Development Economics, 2016, pp. 56-62.

Larreguy, Horacio, “Monitoring Political Brokers: Evidence from Clientelistic Networks in Mexico," 2013. Working paper. 
Larreguy, Horacio A, John Marshall, and James M Snyder Jr, "Publicizing malfeasance: When media facilitates electoral accountability in Mexico," in "paper at Media and Communications conference, the Becker Friedman Institute for Research in Economics, the University of Chicago, November" 2015, pp. 5-6.

Larreguy, Horacio, John Marshall, and Pablo Querubín, "Parties, Brokers, and Voter Mobilization: How Turnout Buying Depends Upon the Party's Capacity to Monitor Brokers," American Political Science Review, 2016, 110 (1), 160-179.

Lawson, Chappell and Kenneth F Greene, "Making clientelism work: How norms of reciprocity increase voter compliance," Comparative Politics, 2014, 47 (1), 61-85.

Lee, David S., Enrico Moretti, and Matthew J. Butler, "Do Voters Affect or Elect Policies? Evidence from the U. S. House," The Quarterly Journal of Economics, 2004, 119, 807-859.

Lehoucq, Fabrice, "When Does a Market for Votes Emerge?," in Frederic Schaffer, ed., Elections for Sale: The Causes and Consequences of Vote Buying, Boulder, Colorado: Lynn Rienner, 2007.

Lenz, Gabriel S., Follow the Leader? How Voters Respond to Politicians' Policies and Performance, Chicago: The University of Chicago Press, 2013.

Llanto, Gilberto M., "The Assignment of Functions and Intergovernmental Fiscal Relations in the Philippines 20 Years after Decentralization," Philippine Review of Economics, 2012, 49 (1), 37-80.

Manski, Charles F., “Measuring Expectations," Econometrica, 2004, 72, 1329-1376.

Nichter, Simeon, "Vote Buying or Turnout Buying? Machine Politics and the Secret Ballot," American Political Science Review, 2008, 102 (1), 19-31.

Ramalho, Esmeralda A. and Richard J. Smith, "Discrete Choice Non-Response," The Review of Economic Studies, 2013, 80 (1), 343-364.

Rubin, D. B., "Estimating Causal Effects of Treatments in Randomized and Nonrandomized Studies," Journal of Education Psychology, 1974, 66, 688-701.

Rubin, Donald B., "Bayesian Inference for Causal Effects: The Role of Randomization," The Annals of Statistics, 1978, 6 (1), 34-58.

Rueda, Miguel R., "Small Aggregates, Big Manipulation: Vote Buying Enforcement and Collective Monitoring," American Journal of Political Science, 2017, 61 (1), 163-177.

Schaffer, Frederic and Andreas Schedler, "What is Vote Buying," in Frederic Schaffer, ed., Elections for Sale: The Causes and Consequences of Vote Buying, Boulder, Colorado: Lynn Rienner, 2007. 
Schaffer, Joby and Andy Baker, "Clientelism as Persuasion-Buying: Evidence from Latin America," Comparative Political Studies, 2015.

Sidel, John, Capital, Coercion, and Crime: Bossism in the Philippines Contemporary Issues in Asia and Pacific, Stanford, CA: Stanford University Press, 1999.

Stokes, Susan C., "Perverse Accountability: A Formal Model of Machine Politics with Evidence from Argentina," The American Political Science Review, 2005, 99 (3), 315-325.

Szwarcberg, Mariela, "Political parties and rallies in Latin America," Party Politics, 2014, 20 (3), 456-466.

Troland, Erin, "Do Fiscal Transfers Increase Local Revenue Collection? Evidence From The Philippines," UCSD, mimeo, 2014.

Vicente, Pedro, "Is Vote Buying Effective? Evidence from a Field Experiment in West Africa," Economic Journal, 2014, 124.

Wantchekon, Leonard, "Clientelism and Voting Behavior: Evidence from a Field Experiment in Benin," World Politics, 2003, 55 (3), 399-422. 


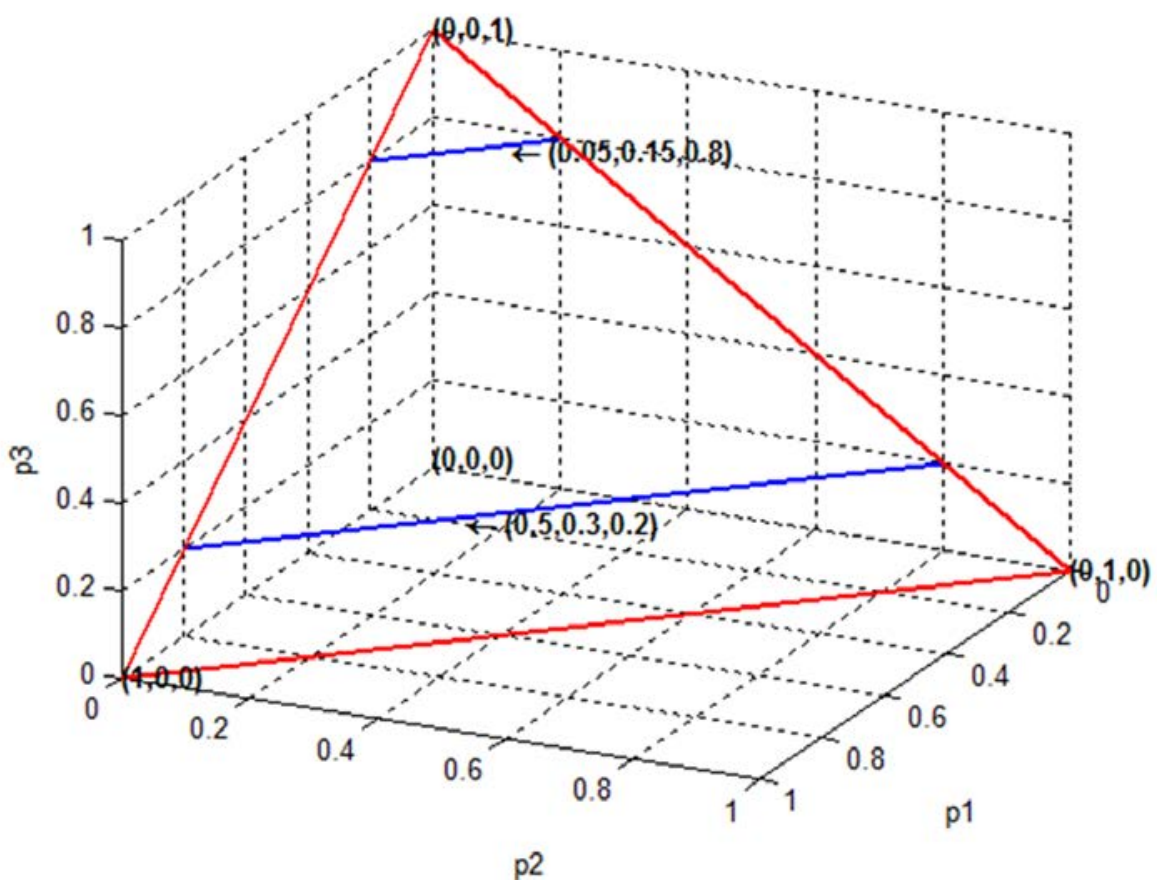

Figure 1: Example of the policy simplex with $K=3$ 


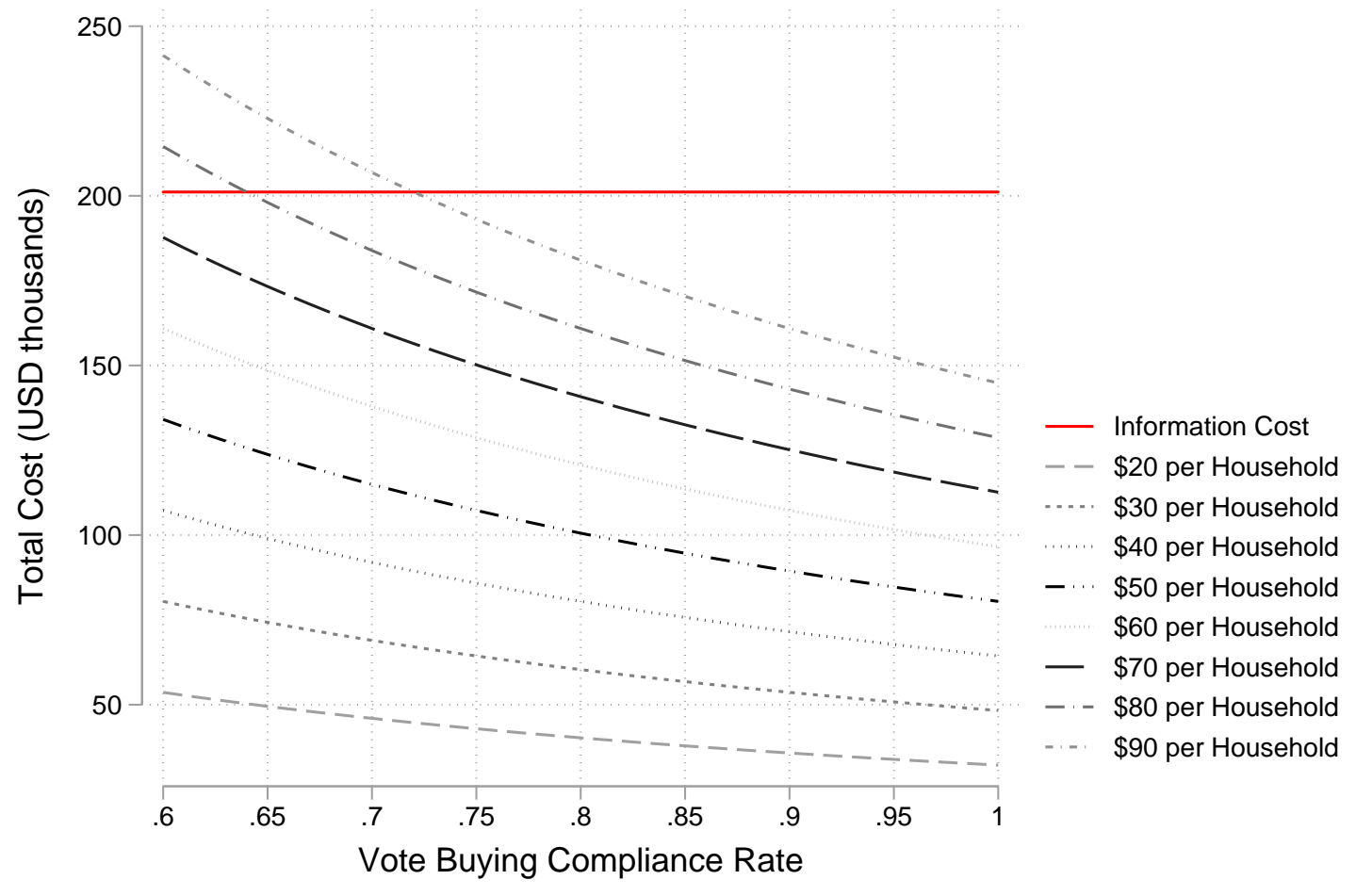

Figure 2: Cost Comparison for Vote Buying and Information Campaigns in a Municipality 
Table 1: Treated voters are more likely to vote for the candidate whose policies are closer to their own preferences.

\begin{tabular}{|c|c|c|c|c|c|}
\hline \multicolumn{6}{|c|}{ Dep var: vote for incumbent } \\
\hline \multirow[t]{2}{*}{ Similarity: } & \multicolumn{3}{|c|}{ Top Sector } & \multirow{2}{*}{$\begin{array}{l}\text { Health, } \\
\text { Edu, Ag. }\end{array}$} & \multirow{2}{*}{$\begin{array}{c}\text { All } \\
\text { Sectors }\end{array}$} \\
\hline & 1 & 2 & 3 & & \\
\hline \multicolumn{6}{|c|}{ Panel A: Overall effects } \\
\hline Treatment & $\begin{array}{c}-0.00048 \\
(0.02)\end{array}$ & $\begin{array}{c}-0.00065 \\
(0.02)\end{array}$ & $\begin{array}{c}-0.00055 \\
(0.02)\end{array}$ & $\begin{array}{c}-0.00075 \\
(0.02)\end{array}$ & $\begin{array}{c}-0.00055 \\
(0.02)\end{array}$ \\
\hline \multirow[t]{2}{*}{$\Delta$ Similarity } & 0.011 & 0.049 & 0.034 & -0.18 & 0.084 \\
\hline & $(0.14)$ & $(0.14)$ & $(0.13)$ & $(0.14)$ & $(0.14)$ \\
\hline \multirow[t]{2}{*}{ Treat $^{*} \Delta$ Similarity } & $0.44^{* *}$ & $0.40^{* *}$ & $0.35^{*}$ & $0.56^{* * *}$ & $0.32^{*}$ \\
\hline & $(0.18)$ & $(0.20)$ & $(0.19)$ & $(0.19)$ & $(0.17)$ \\
\hline Observations & 3155 & 3155 & 3155 & 3155 & 3155 \\
\hline$R^{2}$ & 0.30 & 0.30 & 0.30 & 0.30 & 0.30 \\
\hline \multicolumn{6}{|c|}{ Panel B: Separating the effects of T1 and T2 } \\
\hline \multirow[t]{2}{*}{$\mathrm{T} 1$} & 0.0033 & 0.0033 & 0.0035 & 0.0036 & 0.0038 \\
\hline & $(0.02)$ & $(0.02)$ & $(0.02)$ & $(0.02)$ & $(0.02)$ \\
\hline \multirow[t]{2}{*}{$\mathrm{T} 2$} & -0.0046 & -0.0050 & -0.0050 & -0.0044 & -0.0048 \\
\hline & $(0.02)$ & $(0.02)$ & $(0.02)$ & $(0.02)$ & $(0.02)$ \\
\hline \multirow[t]{2}{*}{$\Delta$ Similarity } & 0.011 & 0.048 & 0.034 & -0.18 & 0.083 \\
\hline & $(0.14)$ & $(0.14)$ & $(0.13)$ & $(0.14)$ & $(0.14)$ \\
\hline \multirow[t]{2}{*}{$\mathrm{T} 1 * \Delta$ Similarity } & $0.59^{* *}$ & $0.62^{* *}$ & $0.54^{*}$ & $0.53^{*}$ & $0.40^{*}$ \\
\hline & $(0.26)$ & $(0.28)$ & $(0.28)$ & $(0.27)$ & $(0.23)$ \\
\hline \multirow[t]{2}{*}{$\mathrm{T} 2 * \Delta$ Similarity } & 0.31 & 0.23 & 0.22 & $0.57^{* * *}$ & 0.26 \\
\hline & $(0.20)$ & $(0.22)$ & $(0.21)$ & $(0.21)$ & $(0.19)$ \\
\hline Observations & 3155 & 3155 & 3155 & 3155 & 3155 \\
\hline$R^{2}$ & 0.30 & 0.30 & 0.30 & 0.30 & 0.30 \\
\hline
\end{tabular}

Notes: Individual-level regressions with triplet fixed effects. The dependent variable is a dummy equal to 1 if the respondent voted for the incumbent in the 2016 mayoral elections. The standard errors (in parentheses) account for potential correlation within village. ${ }^{*}$ denotes significance at the $10 \%,{ }^{* *}$ at the $5 \%$ and, ${ }^{* * *}$ at the $1 \%$ level. 
Table 2: Treated voters are more certain about candidate promises

\begin{tabular}{lcc}
\hline Dep var: & \multicolumn{2}{c}{ Certainty } \\
\hline Treatment & $0.066^{* *}$ & $(0.03)$ \\
& & $0.081^{* *}$ \\
T1 & & $(0.04)$ \\
& & 0.052 \\
T2 & & $(0.04)$ \\
& & \\
& & 3417 \\
Observations & 3417 & 0.03 \\
$R^{2}$ & 0.03 & 0.03 \\
\hline
\end{tabular}

Notes: Individual-level regressions with triplet fixed effects. The dependent variable is certainty of beliefs about expected promises. The standard errors (in parentheses) account for potential correlation within village. * denotes significance at the $10 \%,{ }^{* *}$ at the $5 \%$ and, ${ }^{* * *}$ at the $1 \%$ level. 
Table 3: Treated voters are better informed

\begin{tabular}{|c|c|c|c|c|c|}
\hline \multicolumn{6}{|c|}{ Dep var: Distance between actual promises and expected policies } \\
\hline & \multicolumn{3}{|c|}{ Top Sector } & \multirow{2}{*}{$\begin{array}{l}\text { Health, } \\
\text { Edu, Ag. }\end{array}$} & \multirow{2}{*}{$\begin{array}{c}\text { All } \\
\text { Sectors }\end{array}$} \\
\hline & 1 & 2 & 3 & & \\
\hline \multicolumn{6}{|c|}{ Panel A: Overall effects } \\
\hline Treatment & $\begin{array}{c}-0.0053 \\
(0.003)\end{array}$ & $\begin{array}{r}-0.0030 \\
(0.003)\end{array}$ & $\begin{array}{c}-0.0060^{*} \\
(0.003)\end{array}$ & $\begin{array}{r}-0.0019 \\
(0.003)\end{array}$ & $\begin{array}{c}-0.0059^{*} \\
(0.003)\end{array}$ \\
\hline Obs. & 3414 & 3414 & 3414 & 3414 & 3414 \\
\hline$R^{2}$ & 0.19 & 0.29 & 0.41 & 0.23 & 0.59 \\
\hline \multicolumn{6}{|c|}{ Panel B: Separating the effects of T1 and T2 } \\
\hline $\mathrm{T} 1$ & $\begin{array}{c}-0.0089^{* *} \\
(0.004)\end{array}$ & $\begin{array}{c}-0.0055 \\
(0.004)\end{array}$ & $\begin{array}{c}-0.0088^{* *} \\
(0.004)\end{array}$ & $\begin{array}{c}-0.0048 \\
(0.003)\end{array}$ & $\begin{array}{c}-0.0084^{* *} \\
(0.004)\end{array}$ \\
\hline $\mathrm{T} 2$ & $\begin{array}{c}-0.0020 \\
(0.004)\end{array}$ & $\begin{array}{c}-0.00072 \\
(0.004)\end{array}$ & $\begin{array}{c}-0.0035 \\
(0.004)\end{array}$ & $\begin{array}{c}0.00059 \\
(0.003)\end{array}$ & $\begin{array}{c}-0.0036 \\
(0.004)\end{array}$ \\
\hline Obs. & 3414 & 3414 & 3414 & 3414 & 3414 \\
\hline$R^{2}$ & 0.19 & 0.29 & 0.41 & 0.23 & 0.59 \\
\hline
\end{tabular}

Notes: Individual-level regressions with triplet fixed effects. The dependent variable is is distance between actual promises and voter expected policies. The standard errors (in parentheses) account for potential correlation within village. ${ }^{*}$ denotes significance at the $10 \%,{ }^{* *}$ at the $5 \%$ and, ${ }^{* * *}$ at the $1 \%$ level. 
Table 4: Voters who are reminded of past promises reward incumbents who fulfilled them

\begin{tabular}{lcc}
\hline \multicolumn{3}{c}{ Dep var: vote for incumbent } \\
\hline Treatment & -0.0019 & \\
& $(0.02)$ & \\
Kept & -0.031 & -0.027 \\
& $(0.04)$ & $(0.04)$ \\
Treat * Kept & $0.077^{*}$ & \\
& $(0.04)$ & \\
T1 & & 0.012 \\
& & $(0.03)$ \\
T2 & & -0.015 \\
& & $(0.03)$ \\
T1*Kept & & -0.0025 \\
& & $(0.05)$ \\
T2*Kept & & $0.13^{* *}$ \\
& & $(0.06)$
\end{tabular}

$\begin{array}{lll}\text { Observations } & 2946 & 2946 \\ R^{2} & 0.26 & 0.26\end{array}$

Notes: Individual-level regressions with triplet fixed effects. The dependent variable is a dummy equal to 1 if the respondent voted for the incumbent in the 2016 mayoral elections. The standard errors (in parentheses) account for potential correlation within village. * denotes significance at the $10 \%$, ${ }^{* *}$ at the $5 \%$ and, ${ }^{* * *}$ at the $1 \%$ level. 
Table 5: Incumbents who fulfilled their promises are perceived to more honest and capable in T2 villages

\begin{tabular}{lcccccc}
\hline Dep var: & Approachable & $\begin{array}{c}\text { Experienced } \\
(1)\end{array}$ & $\begin{array}{c}\text { Honest } \\
(2)\end{array}$ & $\begin{array}{c}\text { Connected } \\
(3)\end{array}$ & $\begin{array}{c}\text { Capable } \\
(4)\end{array}$ & $\begin{array}{c}\text { Understands } \\
(6)\end{array}$ \\
\hline T1 & 0.011 & $0.011^{*}$ & 0.0063 & $0.016^{*}$ & 0.0046 & 0.0075 \\
& $(0.02)$ & $(0.01)$ & $(0.01)$ & $(0.01)$ & $(0.01)$ & $(0.01)$ \\
T2 & -0.0020 & -0.0022 & -0.012 & -0.0089 & -0.011 & -0.0050 \\
& $(0.02)$ & $(0.01)$ & $(0.01)$ & $(0.01)$ & $(0.01)$ & $(0.01)$ \\
Kept & -0.0083 & -0.012 & -0.013 & -0.0067 & -0.032 & -0.017 \\
& $(0.03)$ & $(0.02)$ & $(0.02)$ & $(0.02)$ & $(0.02)$ & $(0.02)$ \\
T1*Kept & 0.018 & 0.0030 & 0.018 & 0.017 & 0.012 & 0.0013 \\
& $(0.03)$ & $(0.02)$ & $(0.03)$ & $(0.03)$ & $(0.02)$ & $(0.02)$ \\
T2*Kept & 0.037 & 0.030 & $0.052^{*}$ & 0.026 & $0.070^{* *}$ & 0.031 \\
& $(0.03)$ & $(0.03)$ & $(0.03)$ & $(0.03)$ & $(0.03)$ & $(0.03)$ \\
Observations & & & & & & \\
$R^{2}$ & 3130 & 3140 & 3109 & 3122 & 3129 & 3124 \\
\hline
\end{tabular}

Notes: Individual-level regressions with triplet fixed effects. The dependent variable is a dummy equal to one if incumbent is the candidate that the respondent most associate as being approachable/Friendly (Column 1), being experienced in politics (Column 2), being honest (Column 3), being politically well-connected (Column 4), getting things done (Column 5) understanding the problems of citizens like me (Column 6). The standard errors (in parentheses) account for potential correlation within village. ${ }^{*}$ denotes significance at the $10 \%,{ }^{* *}$ at the $5 \%$ and, ${ }^{* * *}$ at the $1 \%$ level. 
Table 6: Effect of Treatment on links between Perceived Policy Similarity on Incumbent Vote Choice are attenuated for the incumbent's client (ease_medical_expense)

\begin{tabular}{|c|c|c|c|c|c|}
\hline \multicolumn{6}{|l|}{ Dep var: vote for incumbent } \\
\hline \multirow[t]{2}{*}{ Similarity: } & \multicolumn{3}{|c|}{ Top Sector } & \multirow{2}{*}{$\begin{array}{l}\text { Health, } \\
\text { Edu, Ag. }\end{array}$} & \multirow{2}{*}{$\begin{array}{c}\text { All } \\
\text { Sectors }\end{array}$} \\
\hline & 1 & 2 & 3 & & \\
\hline \multirow[t]{2}{*}{ Client } & 0.026 & 0.026 & 0.026 & 0.028 & 0.026 \\
\hline & $(0.03)$ & $(0.03)$ & $(0.03)$ & $(0.03)$ & $(0.03)$ \\
\hline \multirow[t]{2}{*}{$\mathrm{T}^{*}$ Client } & -0.00060 & -0.00049 & -0.00043 & -0.00057 & -0.00099 \\
\hline & $(0.03)$ & $(0.03)$ & $(0.03)$ & $(0.03)$ & $(0.03)$ \\
\hline \multirow[t]{2}{*}{$\mathrm{T}^{*}$ Not Client } & 0.00060 & 0.00038 & 0.000056 & 0.00019 & 0.0010 \\
\hline & $(0.03)$ & $(0.03)$ & $(0.03)$ & $(0.03)$ & $(0.03)$ \\
\hline \multirow[t]{2}{*}{$\Delta$ Similarity ${ }^{*}$ Client } & 0.075 & 0.22 & 0.16 & -0.059 & 0.15 \\
\hline & $(0.18)$ & $(0.18)$ & $(0.15)$ & $(0.16)$ & $(0.14)$ \\
\hline \multirow[t]{2}{*}{$\Delta$ Similarity ${ }^{*}$ Not Client } & -0.098 & -0.17 & -0.16 & -0.37 & -0.028 \\
\hline & $(0.23)$ & $(0.25)$ & $(0.26)$ & $(0.24)$ & $(0.25)$ \\
\hline \multirow[t]{2}{*}{$\mathrm{T}^{*} \Delta$ Similarity ${ }^{*}$ Client } & 0.20 & 0.13 & 0.091 & 0.24 & 0.12 \\
\hline & $(0.27)$ & $(0.28)$ & $(0.26)$ & $(0.25)$ & $(0.24)$ \\
\hline \multirow[t]{2}{*}{$\mathrm{T}^{*} \Delta$ Similarity ${ }^{*}$ Not Client } & $0.65^{* *}$ & $0.68^{* *}$ & $0.62^{* *}$ & $0.89^{* * *}$ & $0.50^{*}$ \\
\hline & $(0.28)$ & $(0.30)$ & $(0.31)$ & $(0.30)$ & $(0.28)$ \\
\hline Observations & 3149 & 3149 & 3149 & 3149 & 3149 \\
\hline$R^{2}$ & 0.30 & 0.30 & 0.30 & 0.30 & 0.30 \\
\hline
\end{tabular}

Notes: Individual-level regressions with triplet fixed effects. The dependent variable is a dummy equal to 1 if the respondent voted for the incumbent in the 2016 mayoral elections. The standard errors (in parentheses) account for potential correlation within village. ${ }^{*}$ denotes significance at the $10 \%,{ }^{* *}$ at the $5 \%$ and, ${ }^{* * *}$ at the $1 \%$ level. 
Table 7: Restricted model with salience

\begin{tabular}{lcc}
\hline & Estimate & Standard Errors \\
\hline$\zeta$ & 0.22 & 0.05 \\
$\alpha$ & 0.37 & 0.09 \\
$\omega$ & 0.71 & 0.22 \\
$\gamma_{1}$ & 1.54 & 0.12 \\
$\gamma_{2}$ & 0.56 & 0.09 \\
$\gamma_{3}$ & 0.82 & 0.17 \\
$\gamma_{4}$ & 0.13 & 0.12 \\
$\gamma_{5}$ & 0.21 & 0.17 \\
$\gamma_{6}$ & 0.93 & 0.21 \\
$\psi_{1}$ & 0.91 & 14.52 \\
$\psi_{2}$ & 0.9 & 0.49 \\
\hline P(response | inc) & 0.97 & 0.01 \\
P(response | chal) & 0.87 & 0.01 \\
\hline
\end{tabular}

Notes: $L L=-2502$. Asymptotic standard errors computed with OPG.Â This model imposes equality of preference parameters across treatment and control groups. The valence parameters are as follows. $\gamma_{1}$ : Approachable; $\gamma_{2}$ : Experienced; $\gamma_{3}$ : Honest $\gamma_{4}$ : Connected; $\gamma_{5}$ : Capable; $\gamma_{6}$ : Understand citizens like me. 
Table 8: Unrestrictred model with salience

\begin{tabular}{lcc}
\hline & Estimate & Standard Errors \\
\hline$\zeta$ & 0.21 & 0.04 \\
$\psi_{1}$ & 1 & 0.32 \\
$\psi_{2}$ & 0.97 & 0.44 \\
$\alpha_{t}$ & 0.28 & 0.11 \\
$\omega_{t}$ & 0.99 & 0.26 \\
$\gamma_{1 t}$ & 1.51 & 0.15 \\
$\gamma_{2 t}$ & 0.59 & 0.1 \\
$\gamma_{3 t}$ & 0.78 & 0.22 \\
$\gamma_{4 t}$ & 0.27 & 0.15 \\
$\gamma_{5 t}$ & 0.32 & 0.21 \\
$\gamma_{6 t}$ & 1.06 & 0.27 \\
$\alpha_{c}$ & 0.54 & 0.15 \\
$\omega_{c}$ & 0.12 & 0.28 \\
$\gamma_{1 c}$ & 1.66 & 0.21 \\
$\gamma_{2 c}$ & 0.55 & 0.16 \\
$\gamma_{3 c}$ & 0.88 & 0.29 \\
$\gamma_{4 c}$ & -0.11 & 0.21 \\
$\gamma_{5 c}$ & -0.06 & 0.29 \\
$\gamma_{6 c}$ & 0.75 & 0.36 \\
\hline p(response|inc) & 0.97 & 0.01 \\
$\mathrm{p}($ response|chal $)$ & 0.87 & 0.01 \\
\hline LR $\chi^{2}(7)$ & & 14.82 \\
& pval & 0.04 \\
\hline
\end{tabular}

Notes: $L L=-2494$. Asymptotic standard errors computed with OPG. Subscript indicates treatment $(t)$ or control (c). Likelihood ratio test with 7 degrees of freedom Â performed against restricted model. The valence parameters are as follows. $\gamma_{1}$ : Approachable; $\gamma_{2}$ : Experienced; $\gamma_{3}$ : Honest $\gamma_{4}$ : Connected; $\gamma_{5}$ : Capable; $\gamma_{6}$ : Understand citizens like me. 
Table 9: Quasirestrictred model with salience

\begin{tabular}{lcc}
\hline & Estimate & Standard Errors \\
\hline$\zeta_{t}$ & 0.21 & 0.04 \\
$\alpha_{t}$ & 0.28 & 0.11 \\
$\omega_{t}$ & 0.99 & 0.26 \\
$\gamma_{1 t}$ & 1.51 & 0.15 \\
$\gamma_{2 t}$ & 0.59 & 0.1 \\
$\gamma_{3 t}$ & 0.78 & 0.22 \\
$\gamma_{4 t}$ & 0.27 & 0.15 \\
$\gamma_{5 t}$ & 0.33 & 0.21 \\
$\gamma_{6 t}$ & 1.06 & 0.27 \\
$\psi_{1 t}$ & 1 & 0.33 \\
$\psi_{2 t}$ & 0.95 & 0.44 \\
$\alpha_{c}$ & 0.55 & 0.15 \\
$\gamma_{1 c}$ & 1.66 & 0.21 \\
$\gamma_{2 c}$ & 0.55 & 0.16 \\
$\gamma_{3 c}$ & 0.88 & 0.29 \\
$\gamma_{4 c}$ & -0.11 & 0.21 \\
$\gamma_{5 c}$ & -0.07 & 0.29 \\
$\gamma_{6 c}$ & 0.75 & 0.36 \\
\hline p(response|inc) & 0.97 & 0.01 \\
p(response|chal) & 0.87 & 0.01 \\
\hline Vuong Test & & 1.676 \\
& pval & 0.047
\end{tabular}

Notes: $L L=-2494$. Asymptotic standard errors computed with OPG. Subscript indicates treatment $(t)$ or control (c). This model imposes that there are no utility effects of beliefs for the control group. Vuong test for non-nested models is performed against the restricted model. The valence parameters are as follows. $\gamma_{1}$ : Approachable; $\gamma_{2}$ : Experienced; $\gamma_{3}$ : Honest $\gamma_{4}$ : Connected; $\gamma_{5}$ : Capable; $\gamma_{6}$ : Understand citizens like me. 


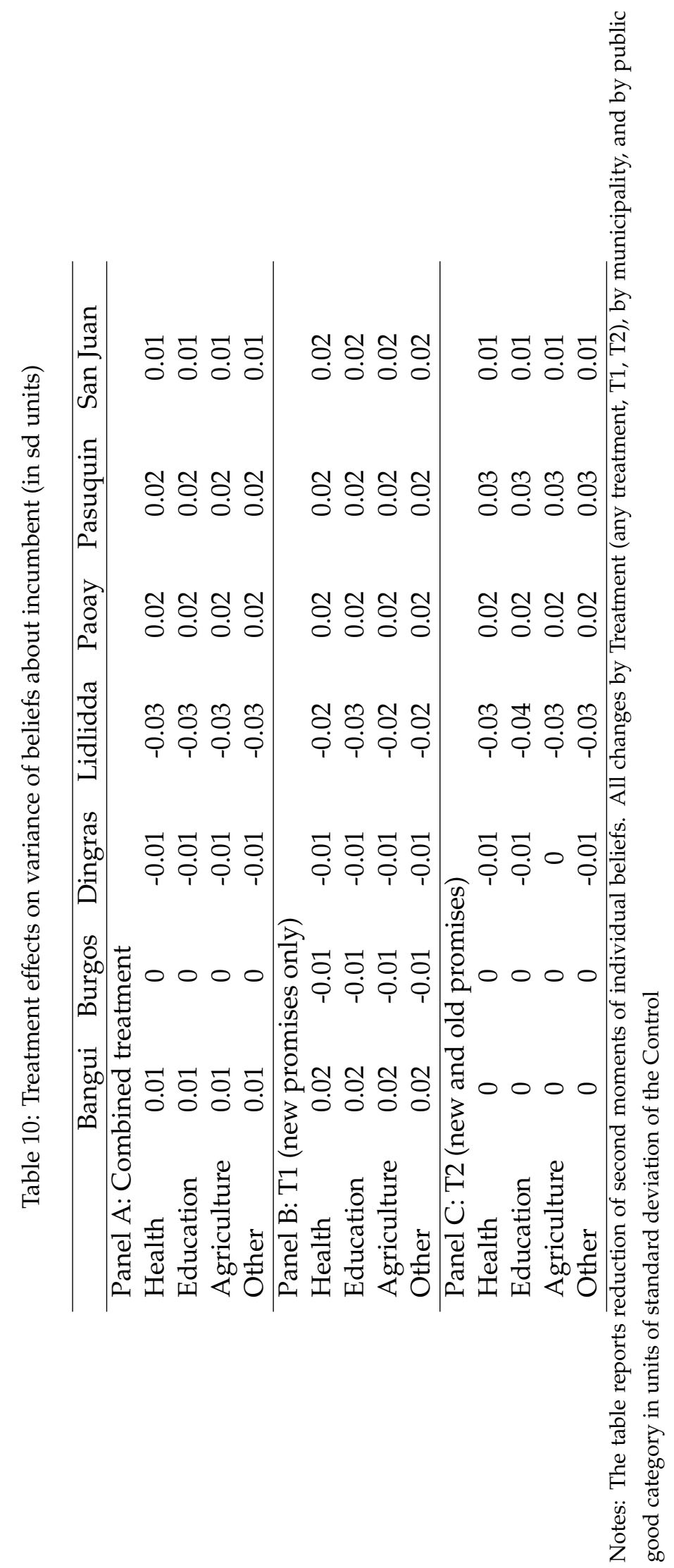


Table 11: Out of sample fit

\begin{tabular}{|c|c|c|c|c|}
\hline & \multicolumn{2}{|c|}{ Inc. Vote Share: } & \multirow{2}{*}{$\begin{array}{c}\text { \% Votes } \\
\text { Correctly Predicted } \\
\text { (3) }\end{array}$} & \multirow{2}{*}{$\begin{array}{c}\text { Out-of-sample } \\
\text { Inc. Vote Share } \\
\text { (4) }\end{array}$} \\
\hline & $\begin{array}{c}\text { Observed } \\
\text { (1) }\end{array}$ & $\begin{array}{c}\text { Estimated } \\
\text { (2) }\end{array}$ & & \\
\hline Bangui & 0.26 & 0.34 & 0.52 & 0.34 \\
\hline Burgos & 0.84 & 0.73 & 0.76 & 0.73 \\
\hline Dingras & 0.89 & 0.73 & 0.9 & 0.65 \\
\hline Lidlidda & 0.73 & 0.48 & 0.61 & 0.47 \\
\hline Paoay & 0.38 & 0.5 & 0.48 & 0.52 \\
\hline Pasuqin & 0.53 & 0.69 & 0.61 & 0.77 \\
\hline San Juan & 0.96 & 0.8 & 0.96 & 0.79 \\
\hline
\end{tabular}

Notes: Column 1 reports the observed vote share for the incumbent. Column 2 reports the average of responding voters probabilities of voting for the incumbent, which represents expected incumbent vote share. Column 3 reports the $\%$ of votes correctly predicted, where for each voter the candidate with the highest estimated probability is chosen as that voter's choice. Column 4 report out of sample estimated incumbent vote share. The municipality is left out of the sample, the model is re-estimated, and the left-out municipality's incumbent vote share is predicted using the estimated parameters. 
Table 12: Counterfactuals

\begin{tabular}{|c|c|c|c|c|c|}
\hline & \multirow{2}{*}{$\begin{array}{c}\text { Inc. Vote Share: } \\
\text { Observed } \\
(1)\end{array}$} & \multicolumn{4}{|c|}{ Estimated Inc. Vote Share under Counterfactual: } \\
\hline & & $\begin{array}{c}\text { No Vote Buying } \\
\text { (2) }\end{array}$ & $\begin{array}{l}\text { Vote Buying Only } \\
\text { (3) }\end{array}$ & $\begin{array}{l}\text { Salience } \\
\text { (4) }\end{array}$ & $\begin{array}{l}\text { Policy } \\
\text { (5) }\end{array}$ \\
\hline Bangui & 0.26 & 0.33 & 0.34 & 0.33 & 0.34 \\
\hline Burgos & 0.84 & 0.71 & 0.53 & 0.74 & 0.73 \\
\hline Dingras & 0.89 & 0.71 & 0.52 & 0.73 & 0.73 \\
\hline Lidlidda & 0.73 & 0.45 & 0.37 & 0.48 & 0.48 \\
\hline Paoay & 0.38 & 0.48 & 0.52 & 0.5 & 0.5 \\
\hline Pasuqin & 0.53 & 0.67 & 0.52 & 0.69 & 0.69 \\
\hline San Juan & 0.96 & 0.79 & 0.54 & 0.8 & 0.8 \\
\hline
\end{tabular}




\section{Appendix for Online Publication}

\section{A.1 Relationship with previous research}

An advantage of our work relative to the literature is in the repeated intervention nature of our informational treatments, which may reduce the threat of confounding endogenous response by candidates due to intrusiveness of the treatment. One-off electoral interventions by foreign NGOs or researchers perceived as extraneous, unfamiliar, and intrusive by incumbent politicians may trigger response by candidates. In related work Cruz et al. (2018), for example, document that this was indeed the case in 2013, with a systematic increase in vote buying efforts by politicians in response to the randomized informational treatments. The authors emphasize how this was a reaction to their RCTs, which employed fliers similar to the ones used in this paper. However, in 2016 we do not observe any systematic and targeted response in vote buying efforts by politicians in response to informational treatments on policy. This is possibly due to the fact that by 2016 political candidates had assumed familiarity with the informational treatments, they all remembered the 2013 intervention, and possibly had even begun to consider policy competition as a viable strategy to garner electoral support (we discuss its cost-effectiveness relative to more traditional electionereeing tools like vote buying in Section 6). Very much alike laboratory experiments, field experiments may require some form of familiarity and conversance, if they are to be used predictively. In this sense our results for the 2016 campaigns are to be considered closer to steady state equilibrium effects.

A reduced-form specification worth exploring involves the role of candidates, not just voters in responding to our treatment. As discussed in the Introduction, we were wary of drastic experimental interventions within political contexts where policy information treatments would be deemed intrusive and deserving of immediate response. Cruz et al. (2018) show that this was indeed the case in 2013, where an experimental informational effort akin to T1 was implemented and a vote buying response by candidates ensued. Cruz et al. (2018) read this evidence as an off-the-hip response of candidates unprepared to the spotlight on public goods, very much akin to the response in a laboratory experiment by subjects exposed to unfamiliar experimental treatment. In much lab experimental analysis, one would discard initial estimates as uninformative, and only focus on evidence under stable conditions of familiarity with the experimental environment. In 2016 one of the first relationship we verified was that the strategic response by incumbents in terms of vote buying had disappeared. In Tables A.21 and A.22 we show that treated voters were neither more nor less likely to be targeted for vote buying. 


\section{Appendix for Online Publication}

A.2 Background on the Experiment 


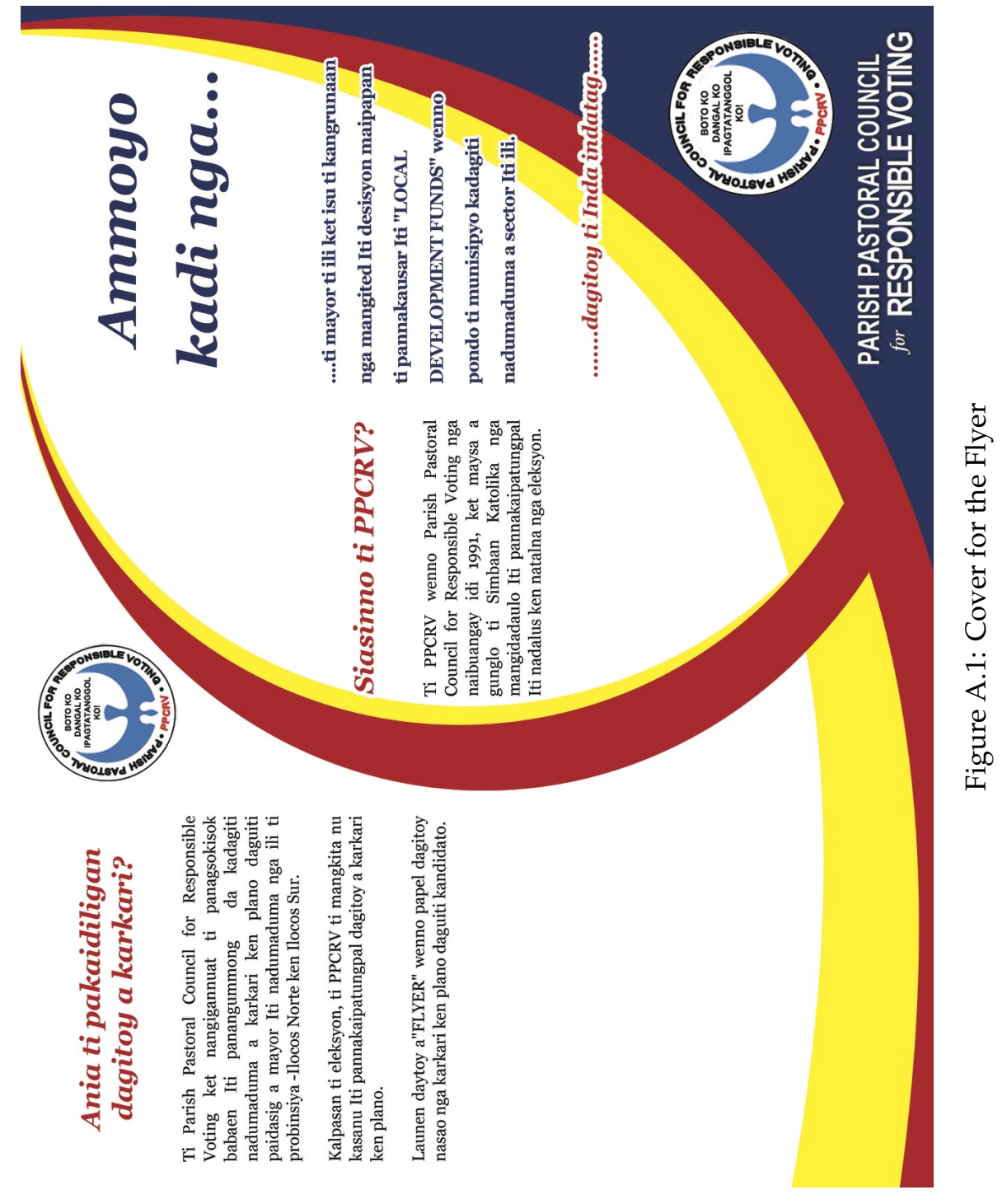




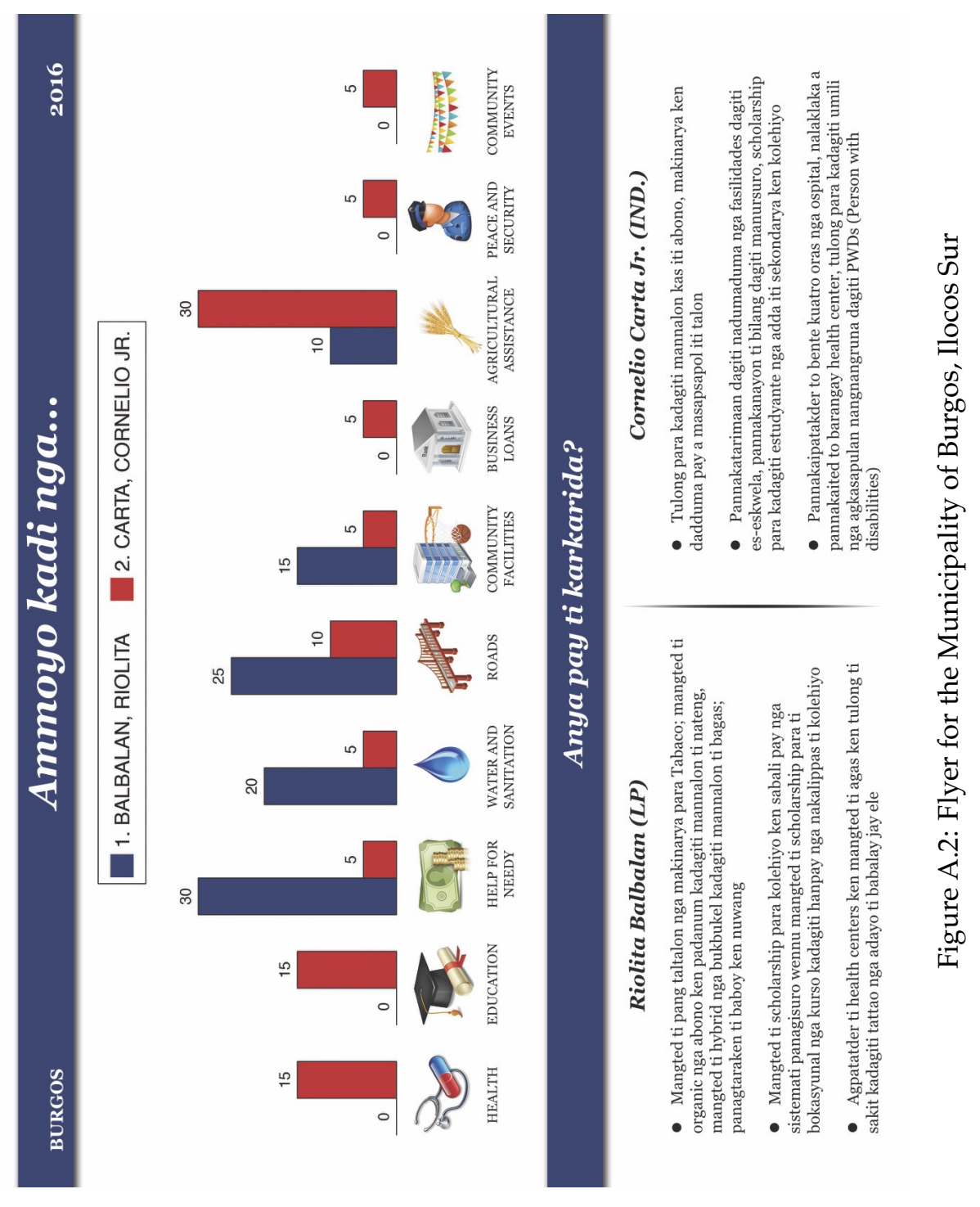


Table A.1: List of Intervention Municipalities

\begin{tabular}{llc}
\hline Province & Municipality & \# Candidates \\
\hline ILOCOS NORTE & BANGUI & 4 \\
& DINGRAS & 2 \\
& PAOAY & 2 \\
& PASUQUIN & 2 \\
\hline ILOCOS SUR & BURGOS & 2 \\
& LIDLIDDA & 3 \\
& SAN JUAN (LAPOG) & 2 \\
\hline
\end{tabular}

Table A.2: Timeline

\begin{tabular}{ll}
\hline Date & Activity \\
\hline April & Candidate interviews \\
May 3-6 & Flyer distribution (door-to-door visits) \\
May 9 & Elections \\
End of May/June & Household survey \\
\hline
\end{tabular}

Table A.3: Translation of Flyer for the Intervention (Fig. A.1)

\begin{tabular}{lll}
\hline Front Page & Inner Flap & Back \\
\hline Did you know... & $\begin{array}{l}\text { What makes these promises } \\
\text { different? }\end{array}$ & About the PPCRV \\
[4ex] The mayor makes im- & The PPCRV collected these Established in 1991, PPCRV is \\
portant decisions about how & promises and the PPCRV will the non-partisan voter educa- \\
money is spent in your mu- & monitor implementation after tion and elections monitoring \\
nicipality. The PPCRV asked the election. The PPCRV arm of the Catholic Church. & the \\
all the candidates for mayor & asked all the mayoral candi- The PPCRV is the leading civil \\
how they would allocate Lo- & dates about the policies and society organization advocat- \\
cal Development Funds across & programs that they will im- ing for free and fair elections \\
sectors. This is what they said: & $\begin{array}{l}\text { plement if elected. This flyer in the Philippines. } \\
\text { presents those proposals. }\end{array}$
\end{tabular}

Note: The inside of the flyer presents the sectoral allocations (with visuals and text in English) as well as additional promises that candidates have opted to convey to voters at the bottom. 
Table A.4: balance tests : voter preferences

\begin{tabular}{lcccccc}
\hline & T1 & T2 & Control & $\beta_{T}$ & $\beta_{T 1}$ & $\beta_{T 2}$ \\
& $(1)$ & $(2)$ & $(3)$ & $(4)$ & $(5)$ & $(6)$ \\
\hline Health & 18.34 & 18.25 & 18.09 & 0.10 & 0.26 & -0.09 \\
& $(13.00)$ & $(11.97)$ & $(12.40)$ & {$[0.82]$} & {$[0.59]$} & {$[0.87]$} \\
Education & 15.80 & 16.56 & 16.21 & -0.19 & -0.40 & 0.05 \\
Help for Needy & $(10.75)$ & $(11.69)$ & $(11.67)$ & {$[0.66]$} & {$[0.42]$} & {$[0.92]$} \\
& 9.18 & 8.90 & 9.07 & -0.03 & 0.12 & -0.19 \\
Water and Sanitation & $(8.64)$ & $(9.02)$ & $(8.77)$ & {$[0.92]$} & {$[0.76]$} & {$[0.56]$} \\
& 8.41 & 8.22 & 8.32 & 0.13 & 0.09 & 0.18 \\
Roads & $(7.61)$ & $(8.55)$ & $(8.06)$ & {$[0.67]$} & {$[0.80]$} & {$[0.63]$} \\
& 11.02 & 10.05 & 10.45 & 0.20 & 0.57 & -0.20 \\
Community Facilities & $(9.96)$ & $(8.72)$ & $(9.99)$ & {$[0.64]$} & {$[0.25]$} & {$[0.69]$} \\
& 6.39 & 5.89 & 6.04 & 0.14 & 0.35 & -0.10 \\
Business Loan & $(6.57)$ & $(6.18)$ & $(6.37)$ & {$[0.57]$} & {$[0.23]$} & {$[0.70]$} \\
Agricultural Assistance & 4.83 & 4.99 & 5.39 & -0.47 & -0.57 & -0.37 \\
& $(6.51)$ & $(6.44)$ & $(7.09)$ & {$[0.03]$} & {$[0.02]$} & {$[0.14]$} \\
Peace and Security & 15.62 & 16.20 & 15.76 & 0.10 & -0.15 & 0.37 \\
& $(12.75)$ & $(12.48)$ & $(13.10)$ & {$[0.85]$} & {$[0.80]$} & {$[0.58]$} \\
Community Events & 6.56 & 7.06 & 6.56 & 0.27 & -0.01 & 0.57 \\
& $(6.27)$ & $(6.26)$ & $(6.53)$ & {$[0.30]$} & {$[0.98]$} & {$[0.07]$} \\
& 3.86 & 3.89 & 4.12 & -0.24 & -0.26 & -0.22 \\
& $(5.24)$ & $(4.79)$ & $(4.79)$ & {$[0.15]$} & {$[0.17]$} & {$[0.25]$} \\
\hline
\end{tabular}

The standard deviations are in (parentheses) (Columns 1-3). Each cell in Columns 4-6 is either the coefficient on the dummy variable indicating whether the treatment (Column 4), treatment 1 (Column 5) or treatment 2 (Column 6) was implemented in the village from a different OLS regression with triplet fixed-effects or the associated p-value in [bracket].

\section{A.3 Additional Results}


Table A.5: balance tests : pairwise matching variables

\begin{tabular}{lcccccc}
\hline & $\mathrm{T} 1$ & $\mathrm{~T} 2$ & Control & $\beta_{T}$ & $\beta_{T 1}$ & $\beta_{\mathrm{T} 2}$ \\
& $(1)$ & $(2)$ & $(3)$ & $(4)$ & $(5)$ & $(6)$ \\
\hline Registered voters & 524.296 & 571.820 & 504.556 & 32.844 & 19.741 & 47.520 \\
& $(367.531)$ & $(390.193)$ & $(294.743)$ & {$[0.518]$} & {$[0.739]$} & {$[0.459]$} \\
Inc. Vote Share (2013) & 51.844 & 52.668 & 50.535 & 1.627 & 1.310 & 1.982 \\
& $(16.307)$ & $(15.211)$ & $(14.376)$ & {$[0.340]$} & {$[0.502]$} & {$[0.329]$} \\
Nb precincts & 1.074 & 1.100 & 1.111 & -0.028 & -0.037 & -0.019 \\
& $(0.328)$ & $(0.364)$ & $(0.317)$ & {$[0.614]$} & {$[0.570]$} & {$[0.785]$} \\
Rural & 0.907 & 0.940 & 0.926 & -0.005 & -0.019 & 0.011 \\
& $(0.293)$ & $(0.240)$ & $(0.264)$ & {$[0.920]$} & {$[0.735]$} & {$[0.842]$} \\
Vote buying (2013) & 0.193 & 0.199 & 0.161 & 0.031 & 0.032 & 0.029 \\
& $(0.182)$ & $(0.195)$ & $(0.174)$ & {$[0.155]$} & {$[0.208]$} & {$[0.276]$} \\
Salience sectors (2013) & 0.792 & 0.808 & 0.697 & 0.100 & 0.095 & 0.105 \\
& $(0.414)$ & $(0.517)$ & $(0.535)$ & {$[0.203]$} & {$[0.254]$} & {$[0.284]$} \\
Knowledge. promises (2013) & 0.068 & 0.064 & 0.011 & 0.049 & 0.057 & 0.041 \\
& $(0.354)$ & $(0.358)$ & $(0.356)$ & {$[0.191]$} & {$[0.147]$} & {$[0.397]$} \\
\hline
\end{tabular}

The standard deviations are in (parentheses) (Columns 1-3). Each cell in Columns 4-6 is either the coefficient on the dummy variable indicating whether the treatment (Column 4), treatment 1 (Column 5) or treatment 2 (Column 6) was implemented in the village from a different OLS regression with triplet fixed-effects or the associated p-value in [bracket]. 
Table A.6: balance tests : HH variables

\begin{tabular}{lcccccc}
\hline & $\mathrm{T} 1$ & $\mathrm{~T} 2$ & Control & $\beta_{T}$ & $\beta_{T 1}$ & $\beta_{T 2}$ \\
& $(1)$ & $(2)$ & $(3)$ & $(4)$ & $(5)$ & $(6)$ \\
\hline Length stay & 34.97 & 36.98 & 36.39 & -0.46 & -1.42 & 0.62 \\
& $(19.97)$ & $(19.73)$ & $(19.85)$ & {$[0.49]$} & {$[0.07]$} & {$[0.39]$} \\
HH size & 5.00 & 5.15 & 5.04 & 0.05 & -0.04 & 0.15 \\
& $(2.26)$ & $(2.26)$ & $(2.07)$ & {$[0.49]$} & {$[0.67]$} & {$[0.11]$} \\
Number kids (0-6) & 0.47 & 0.44 & 0.46 & 0.00 & 0.02 & -0.01 \\
& $(0.82)$ & $(0.79)$ & $(0.77)$ & {$[0.90]$} & {$[0.54]$} & {$[0.65]$} \\
Number kids (6-14) & 0.58 & 0.59 & 0.64 & -0.05 & -0.05 & -0.05 \\
& $(0.98)$ & $(0.99)$ & $(0.99)$ & {$[0.09]$} & {$[0.10]$} & {$[0.18]$} \\
Female & 0.30 & 0.33 & 0.31 & 0.01 & 0.00 & 0.03 \\
& $(0.46)$ & $(0.47)$ & $(0.46)$ & {$[0.61]$} & {$[0.87]$} & {$[0.27]$} \\
Age & 49.23 & 50.49 & 49.85 & 0.06 & -0.55 & 0.76 \\
& $(15.58)$ & $(14.57)$ & $(15.18)$ & {$[0.93]$} & {$[0.50]$} & {$[0.28]$} \\
Education (years) & 9.47 & 9.63 & 9.23 & 0.30 & 0.24 & 0.37 \\
& $(3.48)$ & $(3.49)$ & $(3.53)$ & {$[0.05]$} & {$[0.19]$} & {$[0.03]$} \\
Remittances abroad & 0.31 & 0.34 & 0.32 & 0.01 & -0.01 & 0.03 \\
& $(0.46)$ & $(0.48)$ & $(0.47)$ & {$[0.78]$} & {$[0.54]$} & {$[0.26]$} \\
CCT Beneficiary & 0.19 & 0.19 & 0.20 & -0.01 & -0.01 & 0.00 \\
& $(0.40)$ & $(0.40)$ & $(0.40)$ & {$[0.72]$} & {$[0.67]$} & {$[0.85]$} \\
\hline
\end{tabular}

The standard deviations are in (parentheses) (Columns 1-3). Each cell in Columns 4-6 is either the coefficient on the dummy variable indicating whether the treatment (Column 4), treatment 1 (Column 5) or treatment 2 (Column 6) was implemented in the village from a different OLS regression with triplet fixed-effects or the associated p-value in [bracket]. 
Table A.7: balance tests : match preferences incumbent/voter vs. challenger/voter

\begin{tabular}{lcccccc}
\hline & $\mathrm{T} 1$ & $\mathrm{~T} 2$ & Control & $\beta_{T}$ & $\beta_{T 1}$ & $\beta_{T 2}$ \\
& $(1)$ & $(2)$ & $(3)$ & $(4)$ & $(5)$ & $(6)$ \\
\hline Panel A: Beliefs & & & & & & \\
Top sector & -0.002 & 0.002 & 0.001 & -0.001 & -0.004 & 0.001 \\
& $(0.072)$ & $(0.068)$ & $(0.073)$ & {$[0.558]$} & {$[0.181]$} & {$[0.606]$} \\
Top 2 sectors & -0.002 & 0.002 & -0.001 & 0.000 & -0.001 & 0.002 \\
& $(0.073)$ & $(0.066)$ & $(0.073)$ & {$[0.893]$} & {$[0.594]$} & {$[0.374]$} \\
Top 3 sectors & -0.003 & 0.001 & -0.001 & 0.000 & -0.002 & 0.002 \\
& $(0.073)$ & $(0.066)$ & $(0.076)$ & {$[0.866]$} & {$[0.403]$} & {$[0.507]$} \\
Health/Educ/Ag. & -0.004 & 0.002 & 0.000 & -0.001 & -0.004 & 0.003 \\
& $(0.073)$ & $(0.063)$ & $(0.074)$ & {$[0.775]$} & {$[0.192]$} & {$[0.317]$} \\
All sectors & -0.004 & 0.001 & -0.001 & 0.000 & -0.002 & 0.002 \\
& $(0.085)$ & $(0.076)$ & $(0.088)$ & {$[0.922]$} & {$[0.460]$} & {$[0.501]$} \\
\hline Panel B: Stated Promises & & & & & \\
Top sector & -0.025 & -0.018 & -0.026 & 0.001 & 0.001 & 0.001 \\
& $(0.091)$ & $(0.072)$ & $(0.085)$ & {$[0.676]$} & {$[0.802]$} & {$[0.640]$} \\
Top 2 sectors & -0.034 & -0.026 & -0.036 & 0.001 & 0.002 & 0.001 \\
& $(0.094)$ & $(0.076)$ & $(0.093)$ & {$[0.635]$} & {$[0.593]$} & {$[0.802]$} \\
Top 3 sectors & -0.045 & -0.034 & -0.047 & 0.001 & 0.002 & 0.001 \\
& $(0.102)$ & $(0.083)$ & $(0.104)$ & {$[0.519]$} & {$[0.518]$} & {$[0.675]$} \\
Health/Educ/Ag. & -0.021 & -0.021 & -0.021 & -0.001 & 0.000 & -0.002 \\
& $(0.060)$ & $(0.060)$ & $(0.063)$ & {$[0.787]$} & {$[0.908]$} & {$[0.528]$} \\
All sectors & -0.060 & -0.049 & -0.061 & 0.000 & 0.001 & -0.002 \\
& $(0.119)$ & $(0.103)$ & $(0.120)$ & {$[0.852]$} & {$[0.779]$} & {$[0.522]$} \\
\hline
\end{tabular}

The standard deviations are in (parentheses) (Columns 1-3). Each cell in Columns 4-6 is either the coefficient on the dummy variable indicating whether the treatment (Column 4), treatment 1 (Column 5) or treatment 2 (Column 6) was implemented in the village from a different OLS regression with triplet fixed-effects or the associated p-value in [bracket]. 
Table A.8: Further Descriptive Statistics

\begin{tabular}{lccc}
\hline Variable & Obs. & Mean & Std. Dev. \\
\hline Vote for incumbent & 3,222 & 0.69 & 0.46 \\
Certainty beliefs & 3,189 & 2.93 & 0.85 \\
Approachable & 3,209 & 0.92 & 0.27 \\
Experienced & 3,217 & 0.97 & 0.17 \\
Honest & 3,187 & 0.95 & 0.23 \\
Connected & 3,197 & 0.95 & 0.22 \\
Capable & 3,205 & 0.95 & 0.22 \\
Understand citizens like me & 3,200 & 0.96 & 0.20 \\
Vote buying & 3,189 & 0.40 & 0.49 \\
\hline
\end{tabular}

Notes: The sample is restricted to individuals who responded to the secret ballot question

Table A.9: Comparing Projects Data from the HH Survey and the Accountant/Engineer Survey

\begin{tabular}{lccc}
\hline & \multicolumn{2}{c}{ Household Data } & Accountant/Engineer data \\
& $\begin{array}{c}\text { Village-level } \\
\text { Municipal-level }\end{array}$ & $(3)$ \\
\hline Health & 6.54 & $(2)$ & 4.66 \\
Education & 3.53 & 3.42 & 2.06 \\
Help for Needy & 1.45 & 1.24 & 0.56 \\
Water and Sanitation & 7.68 & 9.27 & 3.78 \\
Roads & 50.39 & 48.97 & 44.45 \\
Community Facilities & 18.47 & 18.52 & 18.68 \\
Business Loan & 0.53 & 0.47 & 1.71 \\
Agricultural Assistance & 5.85 & 5.75 & 6.84 \\
Peace and Security & 4.98 & 5.44 & 3.08 \\
Community Events & 0.59 & 0.71 & 0.03 \\
\hline
\end{tabular}

Notes: Columns 1 and 2 report project shares across the 10 sectors computed from the household survey. Column 3 reports budget shares across the 10 sectors computed from the Accountant/Engineer survey.

Table A.10: Spillovers, certainty

\begin{tabular}{lc}
\hline Dep var: & Certainty \\
\hline Better connected to treatment villages & 0.069 \\
& $(0.08)$ \\
& \\
Observations & 1167 \\
$R^{2}$ & 0.03
\end{tabular}

Notes: Individual-level regressions with municipal fixed effects. The dependent variable is certainty of beliefs about expected promises. The standard errors (in parentheses) account for potential correlation within village. * denotes significance at the $10 \%,{ }^{* *}$ at the $5 \%$ and, ${ }^{* * *}$ at the $1 \%$ level. 
Table A.11: Spillovers, distance, similarity and voting for the incumbent

\begin{tabular}{lccccc}
\hline Sectors: & \multicolumn{3}{c}{ Top Sector } & Health, & $\begin{array}{c}\text { All } \\
\text { Edu, Ag. }\end{array}$ \\
& 1 & 2 & 3 & Sectors \\
\hline Panel A: Distance between beliefs and actual promises & & & \\
Better connected to treatment villages & $-0.011^{*}$ & $-0.011^{*}$ & $-0.0097^{*}$ & $-0.011^{* *}$ & -0.0074 \\
& $(0.01)$ & $(0.01)$ & $(0.01)$ & $(0.00)$ & $(0.01)$ \\
& & & & & \\
Observations & 1167 & 1167 & 1167 & 1167 & 1167 \\
$R^{2}$ & 0.18 & 0.28 & 0.40 & 0.25 & 0.58 \\
\hline Panel B: Vote for the incumbent & & & & & \\
Better connected to treatment villages & $-0.10^{* *}$ & $-0.10^{* *}$ & $-0.10^{* *}$ & $-0.10^{* *}$ & $-0.10^{* *}$ \\
& $(0.04)$ & $(0.04)$ & $(0.04)$ & $(0.04)$ & $(0.04)$ \\
$\Delta$ Similarity & 0.0072 & 0.011 & 0.0096 & -0.0083 & 0.013 \\
& $(0.01)$ & $(0.01)$ & $(0.01)$ & $(0.01)$ & $(0.01)$ \\
$\Delta$ Similarity * & -0.014 & -0.016 & -0.011 & -0.019 & -0.010 \\
Better connected to treatment villages & $(0.02)$ & $(0.02)$ & $(0.02)$ & $(0.02)$ & $(0.02)$ \\
& & & & & \\
Observations & 1071 & 1071 & 1071 & 1071 & 1071 \\
$R^{2}$ & 0.31 & 0.31 & 0.31 & 0.31 & 0.31 \\
\hline
\end{tabular}

Notes: Individual-level regressions with municipal fixed effects. The dependent variable is certainty of beliefs about expected promises. The standard errors (in parentheses) account for potential correlation within village. * denotes significance at the $10 \%,{ }^{* *}$ at the $5 \%$ and, ${ }^{* * *}$ at the $1 \%$ level. 
Table A.12: Treated voters do not appear to shift their preferences to match those of their preferred candidate (actual promises)

\begin{tabular}{|c|c|c|c|c|c|}
\hline & \multicolumn{3}{|c|}{ Top Sector } & \multirow{2}{*}{$\begin{array}{l}\text { Health, } \\
\text { Edu, Ag. }\end{array}$} & \multirow{2}{*}{$\begin{array}{c}\text { All } \\
\text { Sectors }\end{array}$} \\
\hline & 1 & 2 & 3 & & \\
\hline \multicolumn{6}{|c|}{ Panel A: Overall effects } \\
\hline Treatment & $\begin{array}{c}0.0049 \\
(0.00)\end{array}$ & $\begin{array}{c}0.0031 \\
(0.00)\end{array}$ & $\begin{array}{c}0.0034 \\
(0.00)\end{array}$ & $\begin{array}{c}0.00089 \\
(0.00)\end{array}$ & $\begin{array}{c}0.0019 \\
(0.00)\end{array}$ \\
\hline Observations & 3210 & 3210 & 3210 & 3210 & 3210 \\
\hline$R^{2}$ & 0.13 & 0.21 & 0.28 & 0.16 & 0.35 \\
\hline \multicolumn{6}{|c|}{ Panel B: Separating the effects of T1 and T2 } \\
\hline $\mathrm{T} 1$ & $\begin{array}{l}0.0047 \\
(0.00)\end{array}$ & $\begin{array}{c}0.0029 \\
(0.00)\end{array}$ & $\begin{array}{c}0.0041 \\
(0.00)\end{array}$ & $\begin{array}{c}0.0011 \\
(0.00)\end{array}$ & $\begin{array}{c}0.0021 \\
(0.01)\end{array}$ \\
\hline $\mathrm{T} 2$ & $\begin{array}{c}0.0050 \\
(0.00)\end{array}$ & $\begin{array}{c}0.0032 \\
(0.00)\end{array}$ & $\begin{array}{c}0.0028 \\
(0.00)\end{array}$ & $\begin{array}{c}0.00067 \\
(0.00)\end{array}$ & $\begin{array}{c}0.0017 \\
(0.01)\end{array}$ \\
\hline Observations & 3210 & 3210 & 3210 & 3210 & 3210 \\
\hline$R^{2}$ & 0.13 & 0.21 & 0.28 & 0.16 & 0.35 \\
\hline
\end{tabular}

Notes: Individual-level regressions with triplet fixed effects. Dependent variable is our measure of similarity between voter preferences and actual promises (of the candidate they voted for) The standard errors (in parentheses) account for potential correlation within village. ${ }^{*}$ denotes significance at the $10 \%,{ }^{* *}$ at the $5 \%$ and, ${ }^{* * *}$ at the $1 \%$ level. 
Table A.13: Treated voters do not appear to shift their preferences to match those of their preferred candidate (beliefs)

\begin{tabular}{|c|c|c|c|c|c|}
\hline & \multicolumn{3}{|c|}{ Top Sector } & \multirow{2}{*}{$\begin{array}{l}\text { Health, } \\
\text { Edu, Ag. }\end{array}$} & \multirow{2}{*}{$\begin{array}{c}\text { All } \\
\text { Sectors }\end{array}$} \\
\hline & 1 & 2 & 3 & & \\
\hline \multicolumn{6}{|c|}{ Panel A: Overall effects } \\
\hline Treatment & $\begin{array}{c}0.0034 \\
(0.00)\end{array}$ & $\begin{array}{c}0.0014 \\
(0.00)\end{array}$ & $\begin{array}{c}0.0024 \\
(0.00)\end{array}$ & $\begin{array}{c}0.0029 \\
(0.00)\end{array}$ & $\begin{array}{l}0.0027 \\
(0.00)\end{array}$ \\
\hline Observations & 3182 & 3182 & 3182 & 3182 & 3182 \\
\hline$R^{2}$ & 0.05 & 0.05 & 0.04 & 0.04 & 0.04 \\
\hline \multicolumn{6}{|c|}{ Panel B: Separating the effects of $\mathrm{T} 1$ and $\mathrm{T} 2$} \\
\hline $\mathrm{T} 1$ & $\begin{array}{c}0.0052 \\
(0.01)\end{array}$ & $\begin{array}{c}0.0028 \\
(0.01)\end{array}$ & $\begin{array}{c}0.0036 \\
(0.00)\end{array}$ & $\begin{array}{c}0.0030 \\
(0.00)\end{array}$ & $\begin{array}{c}0.0038 \\
(0.01)\end{array}$ \\
\hline $\mathrm{T} 2$ & $\begin{array}{c}0.0019 \\
(0.00)\end{array}$ & $\begin{array}{c}0.00022 \\
(0.00)\end{array}$ & $\begin{array}{c}0.0013 \\
(0.00)\end{array}$ & $\begin{array}{c}0.0028 \\
(0.00)\end{array}$ & $\begin{array}{l}0.0017 \\
(0.01)\end{array}$ \\
\hline Observations & 3182 & 3182 & 3182 & 3182 & 3182 \\
\hline$R^{2}$ & 0.05 & 0.05 & 0.04 & 0.04 & 0.04 \\
\hline
\end{tabular}

Notes: Individual-level regressions with triplet fixed effects. Dependent variable is our measure of similarity between voter preferences and perceived policies (of the candidate they voted for) The standard errors (in parentheses) account for potential correlation within village. * denotes significance at the $10 \%,{ }^{* *}$ at the $5 \%$ and, *** at the $1 \%$ level. 
Table A.14: Estimating the effects separately for incumbents and challengers

\begin{tabular}{lccccc}
\hline DV: vote for incumbent & \multicolumn{5}{c}{ Top Sector } \\
\hline Similarity: & 1 & 2 & 3 & $\begin{array}{c}\text { Health, } \\
\text { Edu, Ag. }\end{array}$ & $\begin{array}{c}\text { All } \\
\text { Sectors }\end{array}$ \\
\hline Treatment & -0.00064 & -0.00090 & -0.00070 & -0.0011 & -0.00069 \\
& $(0.02)$ & $(0.02)$ & $(0.02)$ & $(0.02)$ & $(0.02)$ \\
Similarity Inc. & -0.028 & -0.00085 & 0.0057 & $-0.24^{*}$ & 0.060 \\
& $(0.14)$ & $(0.15)$ & $(0.14)$ & $(0.14)$ & $(0.15)$ \\
Similarity Cha. & -0.053 & -0.10 & -0.070 & 0.11 & -0.11 \\
& $(0.14)$ & $(0.15)$ & $(0.14)$ & $(0.15)$ & $(0.14)$ \\
Treat*Similarity Inc. & $0.45^{* *}$ & $0.43^{* *}$ & $0.38^{*}$ & $0.62^{* * *}$ & $0.32^{*}$ \\
& $(0.18)$ & $(0.20)$ & $(0.20)$ & $(0.20)$ & $(0.19)$ \\
Treat*Similarity Cha. & $-0.42^{* *}$ & $-0.36^{*}$ & -0.33 & $-0.50^{* *}$ & $-0.32^{*}$ \\
& $(0.20)$ & $(0.22)$ & $(0.21)$ & $(0.22)$ & $(0.18)$ \\
Observations & & & & & \\
$R^{2}$ & 3155 & 3155 & 3155 & 3155 & 3155 \\
& 0.30 & 0.30 & 0.30 & 0.30 & 0.30
\end{tabular}

Notes: Individual-level regressions with triplet fixed effects. The dependent variable is a dummy equal to 1 if the respondent voted for the incumbent in the 2016 mayoral elections. The standard errors (in parentheses) account for potential correlation within village. ${ }^{*}$ denotes significance at the $10 \%,{ }^{* *}$ at the $5 \%$ and, ${ }^{* * *}$ at the $1 \%$ level. 
Table A.15: Both stories hold when analyzed simultaneously

\begin{tabular}{|c|c|c|c|c|c|}
\hline \multicolumn{6}{|c|}{ DV: vote for incumbent } \\
\hline \multirow[t]{2}{*}{ Similarity: } & \multicolumn{3}{|c|}{ Top Sector } & \multirow{2}{*}{$\begin{array}{l}\text { Health, } \\
\text { Edu, Ag. }\end{array}$} & \multirow{2}{*}{$\begin{array}{c}\text { All } \\
\text { Sectors }\end{array}$} \\
\hline & 1 & 2 & 3 & & \\
\hline \multirow[t]{2}{*}{ T1 } & 0.010 & 0.011 & 0.011 & 0.011 & 0.011 \\
\hline & $(0.03)$ & $(0.03)$ & $(0.03)$ & $(0.03)$ & $(0.03)$ \\
\hline \multirow[t]{2}{*}{$\mathrm{T} 2$} & -0.016 & -0.016 & -0.016 & -0.016 & -0.015 \\
\hline & $(0.03)$ & $(0.03)$ & $(0.03)$ & $(0.03)$ & $(0.03)$ \\
\hline \multirow[t]{2}{*}{$\Delta$ Similarity } & -0.051 & 0.0099 & 0.000006 & -0.22 & 0.050 \\
\hline & $(0.14)$ & $(0.16)$ & $(0.15)$ & $(0.15)$ & $(0.15)$ \\
\hline \multirow[t]{2}{*}{$\mathrm{T} 1^{*} \Delta$ Similarity } & $0.59^{* *}$ & $0.63^{* *}$ & $0.53^{*}$ & $0.51^{*}$ & $0.44^{*}$ \\
\hline & $(0.28)$ & $(0.31)$ & $(0.31)$ & $(0.29)$ & $(0.25)$ \\
\hline \multirow[t]{2}{*}{$\mathrm{T} 2 * \Delta$ Similarity } & 0.34 & 0.21 & 0.19 & $0.56^{* *}$ & 0.22 \\
\hline & $(0.24)$ & $(0.26)$ & $(0.25)$ & $(0.25)$ & $(0.22)$ \\
\hline \multirow[t]{2}{*}{ Kept } & -0.025 & -0.023 & -0.024 & -0.025 & -0.023 \\
\hline & $(0.05)$ & $(0.05)$ & $(0.05)$ & $(0.05)$ & $(0.05)$ \\
\hline \multirow[t]{2}{*}{$\mathrm{T} 1{ }^{*} \mathrm{Kept}$} & 0.0033 & 0.0051 & 0.0050 & 0.0027 & 0.0036 \\
\hline & $(0.05)$ & $(0.05)$ & $(0.05)$ & $(0.05)$ & $(0.05)$ \\
\hline \multirow[t]{2}{*}{$\mathrm{T} 2 *$ Kept } & $0.13^{* *}$ & $0.12^{* *}$ & $0.12^{* *}$ & $0.12^{* *}$ & $0.12^{* *}$ \\
\hline & $(0.06)$ & $(0.06)$ & $(0.06)$ & $(0.06)$ & $(0.06)$ \\
\hline Observations & 2885 & 2885 & 2885 & 2885 & 2885 \\
\hline$R^{2}$ & 0.27 & 0.27 & 0.26 & 0.26 & 0.27 \\
\hline
\end{tabular}

Notes: Individual-level regressions with triplet fixed effects. The dependent variable is a dummy equal to 1 if the respondent voted for the incumbent in the 2016 mayoral elections. The standard errors (in parentheses) account for potential correlation within village. ${ }^{*}$ denotes significance at the $10 \%,{ }^{* *}$ at the $5 \%$ and, ${ }^{* * *}$ at the $1 \%$ level. 
Table A.16: Voters who are reminded of past promises reward incumbents who fulfilled them (controlling for number of projects)

\begin{tabular}{lcc}
\hline \multicolumn{3}{l}{ Dep var: vote for incumbent } \\
\hline Treatment & -0.00068 & \\
& $(0.02)$ & \\
Kept & -0.041 & -0.035 \\
& $(0.04)$ & $(0.04)$ \\
T*Kept & $0.090^{*}$ & \\
& $(0.05)$ & \\
\# Projects (2013/16) & $0.0059^{*}$ & $0.0060^{*}$ \\
& $(0.00)$ & $(0.00)$ \\
T*\# Projects (2013/16) & -0.0055 & \\
& $(0.00)$ & \\
T1 & & 0.014 \\
& & $(0.03)$ \\
T2 & & -0.013 \\
& & $(0.03)$ \\
T1*Kept & & 0.022 \\
& & $(0.06)$ \\
T2*Kept & & $0.14^{* *}$ \\
& & $(0.06)$ \\
T1*\# Projects $(2013 / 16)$ & & -0.0032 \\
& & $(0.00)$ \\
T2*\# Projects $(2013 / 16)$ & & $-0.0066^{*}$ \\
& & $(0.00)$ \\
Observations & & 2946 \\
$R^{2}$ & & 0.26 \\
\hline
\end{tabular}

Notes: Individual-level regressions with triplet fixed effects. The dependent variable is a dummy equal to 1 if the respondent voted for the incumbent in the 2016 mayoral elections. The standard errors (in parentheses) account for potential correlation within village. ${ }^{*}$ denotes significance at the $10 \%,{ }^{* *}$ at the $5 \%$ and, ${ }^{* * *}$ at the $1 \%$ level. 
Table A.17: Incumbents who fulfilled their promises are perceived to more honest and capable in T2 villages (controlling for number of projects)

\begin{tabular}{lcccccc}
\hline Dep var: & & & & & \\
& Approachable & Experienced & Honest & Connected & Capable & Understands \\
& $(1)$ & $(2)$ & $(3)$ & $(4)$ & $(5)$ & $(6)$ \\
\hline T1 & 0.00049 & $0.011^{*}$ & 0.0030 & $0.016^{*}$ & 0.0018 & 0.0056 \\
& $(0.01)$ & $(0.01)$ & $(0.01)$ & $(0.01)$ & $(0.01)$ & $(0.01)$ \\
T2 & 0.0030 & -0.0024 & -0.011 & -0.0097 & -0.011 & -0.0047 \\
& $(0.02)$ & $(0.01)$ & $(0.01)$ & $(0.01)$ & $(0.01)$ & $(0.01)$ \\
Kept & -0.030 & -0.011 & -0.019 & -0.0061 & $-0.036^{*}$ & -0.020 \\
& $(0.02)$ & $(0.02)$ & $(0.02)$ & $(0.02)$ & $(0.02)$ & $(0.02)$ \\
T1*Kept & 0.039 & -0.00065 & 0.024 & 0.0099 & 0.010 & 0.00044 \\
& $(0.03)$ & $(0.02)$ & $(0.02)$ & $(0.02)$ & $(0.02)$ & $(0.02)$ \\
T2*Kept & 0.044 & 0.027 & $0.053^{* *}$ & 0.022 & $0.068^{* *}$ & 0.030 \\
& $(0.03)$ & $(0.03)$ & $(0.03)$ & $(0.03)$ & $(0.03)$ & $(0.03)$ \\
\# Projects (2013/16) & -0.00087 & -0.00089 & -0.00075 & -0.00056 & -0.00064 & -0.00030 \\
& $(0.00)$ & $(0.00)$ & $(0.00)$ & $(0.00)$ & $(0.00)$ & $(0.00)$ \\
T1*\# Projects (2013/16) & $-0.0065^{* * *}$ & 0.00036 & -0.0014 & -0.00075 & $-0.0022^{*}$ & -0.0017 \\
& $(0.00)$ & $(0.00)$ & $(0.00)$ & $(0.00)$ & $(0.00)$ & $(0.00)$ \\
T2*\# Projects (2013/16) & $-0.0065^{* * *}$ & 0.0011 & -0.0015 & 0.0016 & -0.000043 & -0.00017 \\
& $(0.00)$ & $(0.00)$ & $(0.00)$ & $(0.00)$ & $(0.00)$ & $(0.00)$ \\
\hline Observations & 3130 & 3140 & 3109 & 3122 & 3129 & 3124 \\
$R^{2}$ & 0.05 & 0.06 & 0.03 & 0.03 & 0.03 & 0.03 \\
\hline
\end{tabular}

Notes: Individual-level regressions with triplet fixed effects. The dependent variable is a dummy equal to one if incumbent is the candidate that the respondent most associate as being approachable/Friendly (Column 1), being experienced in politics (Column 2), being honest (Column 3), being politically well-connected (Column 4), getting things done (Column 5) understanding the problems of citizens like me (Column 6). The standard errors (in parentheses) account for potential correlation within village. ${ }^{*}$ denotes significance at the $10 \%$, ${ }^{* *}$ at the $5 \%$ and, ${ }^{* * *}$ at the $1 \%$ level. 
Table A.18: Effect of Treatment on links between Perceived Policy Similarity on Incumbent Vote Choice are attenuated for the incumbent's client (ease_endorsement_letter)

\begin{tabular}{|c|c|c|c|c|c|}
\hline \multicolumn{6}{|c|}{ Dep var: vote for incumbent } \\
\hline \multirow[t]{2}{*}{ Similarity: } & \multicolumn{3}{|c|}{ Top Sector } & \multirow{2}{*}{$\begin{array}{l}\text { Health, } \\
\text { Edu, Ag. }\end{array}$} & \multirow{2}{*}{$\begin{array}{c}\text { All } \\
\text { Sectors }\end{array}$} \\
\hline & 1 & 2 & 3 & & \\
\hline \multirow{2}{*}{ Client } & 0.028 & 0.029 & 0.029 & 0.030 & 0.029 \\
\hline & $(0.03)$ & $(0.03)$ & $(0.03)$ & $(0.03)$ & $(0.03)$ \\
\hline \multirow[t]{2}{*}{$\mathrm{T}^{*}$ Client } & -0.020 & -0.019 & -0.019 & -0.019 & -0.021 \\
\hline & $(0.03)$ & $(0.03)$ & $(0.03)$ & $(0.03)$ & $(0.03)$ \\
\hline \multirow[t]{2}{*}{$\mathrm{T}^{*}$ Not Client } & 0.0086 & 0.0088 & 0.0084 & 0.0090 & 0.0088 \\
\hline & $(0.02)$ & $(0.02)$ & $(0.02)$ & $(0.02)$ & $(0.02)$ \\
\hline \multirow[t]{2}{*}{$\Delta$ Similarity ${ }^{*}$ Client } & 0.24 & 0.23 & 0.15 & 0.12 & 0.12 \\
\hline & $(0.16)$ & $(0.15)$ & $(0.13)$ & $(0.17)$ & $(0.15)$ \\
\hline \multirow[t]{2}{*}{$\Delta$ Similarity ${ }^{*}$ Not Client } & -0.20 & -0.15 & -0.13 & $-0.49 * *$ & 0.0094 \\
\hline & $(0.20)$ & $(0.21)$ & $(0.22)$ & $(0.20)$ & $(0.22)$ \\
\hline \multirow[t]{2}{*}{$\mathrm{T}^{*} \Delta$ Similarity ${ }^{*}$ Client } & 0.038 & -0.019 & 0.0066 & 0.084 & 0.15 \\
\hline & $(0.28)$ & $(0.29)$ & $(0.28)$ & $(0.27)$ & $(0.27)$ \\
\hline \multirow[t]{2}{*}{$\mathrm{T}^{*} \Delta$ Similarity ${ }^{*}$ Not Client } & $0.71^{* * *}$ & $0.69^{* * *}$ & $0.61^{* *}$ & $0.95^{* * *}$ & $0.45^{*}$ \\
\hline & $(0.24)$ & $(0.26)$ & $(0.27)$ & $(0.25)$ & $(0.25)$ \\
\hline Observations & 3144 & 3144 & 3144 & 3144 & 3144 \\
\hline$R^{2}$ & 0.30 & 0.30 & 0.30 & 0.30 & 0.30 \\
\hline
\end{tabular}

Notes: Individual-level regressions with triplet fixed effects. The dependent variable is a dummy equal to 1 if the respondent voted for the incumbent in the 2016 mayoral elections. The standard errors (in parentheses) account for potential correlation within village. ${ }^{*}$ denotes significance at the $10 \%,{ }^{* *}$ at the $5 \%$ and, ${ }^{* * *}$ at the $1 \%$ level. 
Table A.19: Effect of Treatment on links between Perceived Policy Similarity on Incumbent Vote Choice are attenuated for the incumbent's client (ease_funeral_expense)

\begin{tabular}{|c|c|c|c|c|c|}
\hline \multicolumn{6}{|l|}{ Dep var: vote for incumbent } \\
\hline \multirow[t]{2}{*}{ Similarity: } & \multicolumn{3}{|c|}{ Top Sector } & \multirow{2}{*}{$\begin{array}{l}\text { Health, } \\
\text { Edu, Ag. }\end{array}$} & \multirow{2}{*}{$\begin{array}{c}\text { All } \\
\text { Sectors }\end{array}$} \\
\hline & 1 & 2 & 3 & & \\
\hline \multirow[t]{2}{*}{ Client } & 0.028 & 0.028 & 0.029 & 0.029 & 0.028 \\
\hline & $(0.03)$ & $(0.03)$ & $(0.03)$ & $(0.03)$ & $(0.03)$ \\
\hline \multirow[t]{2}{*}{$\mathrm{T}^{*}$ Client } & 0.0055 & 0.0058 & 0.0064 & 0.0057 & 0.0055 \\
\hline & $(0.03)$ & $(0.03)$ & $(0.03)$ & $(0.03)$ & $(0.03)$ \\
\hline \multirow[t]{2}{*}{$\mathrm{T}^{*}$ Not Client } & -0.0016 & -0.0021 & -0.0022 & -0.0021 & -0.0020 \\
\hline & $(0.03)$ & $(0.03)$ & $(0.03)$ & $(0.03)$ & $(0.03)$ \\
\hline \multirow[t]{2}{*}{$\Delta^{*}$ Similarity ${ }^{*}$ Client } & 0.018 & 0.082 & 0.049 & -0.16 & 0.039 \\
\hline & $(0.21)$ & $(0.19)$ & $(0.16)$ & $(0.20)$ & $(0.16)$ \\
\hline \multirow[t]{2}{*}{$\Delta^{*}$ Similarity*Not Client } & -0.012 & -0.020 & -0.019 & -0.26 & 0.092 \\
\hline & $(0.22)$ & $(0.24)$ & $(0.25)$ & $(0.23)$ & $(0.23)$ \\
\hline \multirow[t]{2}{*}{$\mathrm{T}^{*} \Delta^{*}$ Similarity ${ }^{*}$ Client } & 0.23 & 0.16 & 0.11 & 0.33 & 0.21 \\
\hline & $(0.30)$ & $(0.31)$ & $(0.30)$ & $(0.32)$ & $(0.26)$ \\
\hline \multirow[t]{2}{*}{$\mathrm{T}^{*} \Delta^{*}$ Similarity ${ }^{*}$ Not Client } & $0.56^{* *}$ & $0.57^{* *}$ & $0.51^{*}$ & $0.76^{* * *}$ & 0.37 \\
\hline & $(0.26)$ & $(0.27)$ & $(0.28)$ & $(0.27)$ & $(0.26)$ \\
\hline Observations & 3145 & 3145 & 3145 & 3145 & 3145 \\
\hline$R^{2}$ & 0.30 & 0.30 & 0.30 & 0.30 & 0.30 \\
\hline
\end{tabular}

Notes: Individual-level regressions with triplet fixed effects. The dependent variable is a dummy equal to 1 if the respondent voted for the incumbent in the 2016 mayoral elections. The standard errors (in parentheses) account for potential correlation within village. ${ }^{*}$ denotes significance at the $10 \%,{ }^{* *}$ at the $5 \%$ and, ${ }^{* * *}$ at the $1 \%$ level. 
Table A.20: Effect of Treatment on links between Perceived Policy Similarity on Incumbent Vote Choice are attenuated for the incumbent's client (related_politics)

\begin{tabular}{|c|c|c|c|c|c|}
\hline \multicolumn{6}{|l|}{ Dep var: vote for incumbent } \\
\hline \multirow[t]{2}{*}{ Similarity: } & \multicolumn{3}{|c|}{ Top Sector } & \multirow{2}{*}{$\begin{array}{l}\text { Health, } \\
\text { Edu, Ag. }\end{array}$} & \multirow{2}{*}{$\begin{array}{c}\text { All } \\
\text { Sectors }\end{array}$} \\
\hline & 1 & 2 & 3 & & \\
\hline \multirow[t]{2}{*}{ Client } & -0.043 & -0.043 & -0.043 & -0.043 & -0.043 \\
\hline & $(0.03)$ & $(0.03)$ & $(0.03)$ & $(0.03)$ & $(0.03)$ \\
\hline \multirow[t]{2}{*}{$\mathrm{T}^{*}$ Client } & 0.045 & 0.044 & 0.044 & 0.044 & 0.044 \\
\hline & $(0.04)$ & $(0.04)$ & $(0.04)$ & $(0.04)$ & $(0.04)$ \\
\hline \multirow[t]{2}{*}{$\mathrm{T}^{*}$ Not Client } & -0.0093 & -0.0093 & -0.0092 & -0.0095 & -0.0092 \\
\hline & $(0.02)$ & $(0.02)$ & $(0.02)$ & $(0.02)$ & $(0.02)$ \\
\hline \multirow[t]{2}{*}{$\Delta^{*}$ Similarity ${ }^{*}$ Client } & 0.28 & 0.064 & 0.019 & 0.030 & -0.056 \\
\hline & $(0.29)$ & $(0.29)$ & $(0.31)$ & $(0.22)$ & $(0.28)$ \\
\hline \multirow[t]{2}{*}{$\Delta^{*}$ Similarity*Not Client } & -0.037 & 0.046 & 0.037 & -0.22 & 0.10 \\
\hline & $(0.16)$ & $(0.16)$ & $(0.14)$ & $(0.16)$ & $(0.15)$ \\
\hline \multirow[t]{2}{*}{$\mathrm{T}^{*} \Delta^{*}$ Similarity ${ }^{*}$ Client } & 0.014 & -0.0022 & -0.0092 & 0.25 & 0.20 \\
\hline & $(0.50)$ & $(0.48)$ & $(0.48)$ & $(0.53)$ & $(0.40)$ \\
\hline \multirow[t]{2}{*}{$\mathrm{T}^{*} \Delta^{*}$ Similarity ${ }^{*}$ Not Client } & $0.51^{* *}$ & $0.48^{* *}$ & $0.43^{* *}$ & $0.61^{* * *}$ & $0.34^{*}$ \\
\hline & $(0.20)$ & $(0.20)$ & $(0.20)$ & $(0.20)$ & $(0.19)$ \\
\hline Observations & 3155 & 3155 & 3155 & 3155 & 3155 \\
\hline$R^{2}$ & 0.30 & 0.30 & 0.30 & 0.30 & 0.30 \\
\hline
\end{tabular}

Notes: Individual-level regressions with triplet fixed effects. The dependent variable is a dummy equal to 1 if the respondent voted for the incumbent in the 2016 mayoral elections. The standard errors (in parentheses) account for potential correlation within village. ${ }^{*}$ denotes significance at the $10 \%,{ }^{* *}$ at the $5 \%$ and, ${ }^{* * *}$ at the $1 \%$ level. 
Table A.21: Treated voters are not more likely to be targeted for vote buying.

\begin{tabular}{|c|c|c|c|c|}
\hline \multicolumn{5}{|c|}{ Dep var: targeted for vote-buying } \\
\hline Treatment & $\begin{array}{c}-0.0015 \\
(0.03)\end{array}$ & & $\begin{array}{l}-0.023 \\
(0.03)\end{array}$ & \\
\hline $\mathrm{T} 1$ & & $\begin{array}{c}0.0074 \\
(0.03)\end{array}$ & & $\begin{array}{l}-0.013 \\
(0.04)\end{array}$ \\
\hline $\mathrm{T} 2$ & & $\begin{array}{c}-0.0096 \\
(0.03)\end{array}$ & & $\begin{array}{l}-0.031 \\
(0.04)\end{array}$ \\
\hline Kept & & & $\begin{array}{c}-0.13^{* *} \\
(0.06)\end{array}$ & $\begin{array}{c}-0.13^{* *} \\
(0.06)\end{array}$ \\
\hline $\mathrm{T}^{*} \mathrm{Kept}$ & & & $\begin{array}{l}0.055 \\
(0.08)\end{array}$ & \\
\hline T1*Kept & & & & $\begin{array}{l}0.032 \\
(0.10)\end{array}$ \\
\hline $\mathrm{T} 2 * \mathrm{Kept}$ & & & & $\begin{array}{l}0.071 \\
(0.09) \\
\end{array}$ \\
\hline Observations & 3423 & 3423 & 3111 & 3111 \\
\hline$R^{2}$ & 0.12 & 0.12 & 0.12 & 0.12 \\
\hline
\end{tabular}

Notes: Individual-level regressions with triplet fixed effects. The dependent variable is a dummy equal to one if the respondent was targeted for vote-buying. The standard errors (in parentheses) account for potential correlation within village. ${ }^{*}$ denotes significance at the $10 \%,{ }^{* *}$ at the $5 \%$ and, ${ }^{* * *}$ at the $1 \%$ level. 
Table A.22: Treated voters are not more likely to be targeted for vote buying.

\begin{tabular}{|c|c|c|c|c|c|}
\hline \multicolumn{6}{|c|}{ Dep var: targeted for vote-buying } \\
\hline \multirow[t]{2}{*}{ Similarity: } & \multicolumn{3}{|c|}{ Top Sector } & \multirow{2}{*}{$\begin{array}{l}\text { Health, } \\
\text { Edu, Ag. }\end{array}$} & \multirow{2}{*}{$\begin{array}{c}\text { All } \\
\text { Sectors }\end{array}$} \\
\hline & 1 & 2 & 3 & & \\
\hline \multicolumn{6}{|l|}{ Panel A } \\
\hline Treatment & $\begin{array}{c}-0.00053 \\
(0.03)\end{array}$ & $\begin{array}{c}-0.00066 \\
(0.03)\end{array}$ & $\begin{array}{c}-0.00044 \\
(0.03)\end{array}$ & $\begin{array}{c}-0.00040 \\
(0.03)\end{array}$ & $\begin{array}{c}-0.00014 \\
(0.03)\end{array}$ \\
\hline \multirow[t]{2}{*}{$\Delta$ Similarity } & -0.0050 & 0.095 & -0.0015 & 0.0046 & 0.037 \\
\hline & $(0.21)$ & $(0.19)$ & $(0.21)$ & $(0.25)$ & $(0.20)$ \\
\hline \multirow[t]{2}{*}{$\mathrm{T}^{*} \Delta$ Similarity } & 0.31 & 0.12 & 0.24 & 0.26 & 0.25 \\
\hline & $(0.25)$ & $(0.24)$ & $(0.25)$ & $(0.31)$ & $(0.23)$ \\
\hline Observations & 3409 & 3409 & 3409 & 3409 & 3409 \\
\hline$R^{2}$ & 0.12 & 0.12 & 0.12 & 0.12 & 0.12 \\
\hline \multicolumn{6}{|l|}{ Panel B } \\
\hline \multirow[t]{2}{*}{$\mathrm{T} 1$} & 0.0089 & 0.0086 & 0.0087 & 0.0084 & 0.0085 \\
\hline & $(0.03)$ & $(0.03)$ & $(0.03)$ & $(0.03)$ & $(0.03)$ \\
\hline \multirow[t]{2}{*}{$\mathrm{T} 2$} & -0.0071 & -0.0073 & -0.0073 & -0.0079 & -0.0072 \\
\hline & $(0.03)$ & $(0.03)$ & $(0.03)$ & $(0.03)$ & $(0.03)$ \\
\hline \multirow[t]{2}{*}{$\Delta$ Similarity } & 0.093 & 0.12 & 0.060 & 0.0061 & 0.035 \\
\hline & (0.19) & $(0.20)$ & $(0.18)$ & $(0.19)$ & $(0.15)$ \\
\hline \multirow[t]{2}{*}{$\mathrm{T} 1^{*} \Delta$ Similarity } & 0.044 & 0.073 & 0.083 & 0.19 & 0.16 \\
\hline & $(0.29)$ & $(0.29)$ & $(0.28)$ & $(0.27)$ & $(0.25)$ \\
\hline \multirow[t]{2}{*}{$\mathrm{T} 2 * \Delta$ Similarity } & -0.15 & -0.23 & -0.14 & -0.22 & -0.057 \\
\hline & $(0.27)$ & $(0.28)$ & $(0.26)$ & $(0.25)$ & $(0.23)$ \\
\hline Observations & 3334 & 3334 & 3334 & 3334 & 3334 \\
\hline$R^{2}$ & 0.12 & 0.12 & 0.12 & 0.12 & 0.12 \\
\hline
\end{tabular}

Notes: Individual-level regressions with triplet fixed effects. The dependent variable is a dummy equal to one if the respondent was targeted for vote-buying. The standard errors (in parentheses) account for potential correlation within village. ${ }^{*}$ denotes significance at the $10 \%,{ }^{* *}$ at the $5 \%$ and, ${ }^{* * *}$ at the $1 \%$ level. 